\title{
The parasitic dinoflagellates Blastodinium spp. inhabiting the gut of marine, planktonic copepods: morphology, ecology, and unrecognized species diversity
}

\author{
Alf Skovgaard ${ }^{1}$ *, Sergey A. Karpov ${ }^{2,3}$ and Laure Guillou ${ }^{4,5}$ \\ 1 Laboratory of Aquatic Pathobiology, Department of Veterinary Disease Biology, University of Copenhagen, Frederiksberg, Denmark \\ ${ }^{2}$ Zoological Institute of the Russian Academy of Sciences, St. Petersburg, Russia \\ ${ }^{3}$ St. Petersburg State University, St. Petersburg, Russia \\ ${ }^{4}$ Station Biologique de Roscoff, Université Pierre et Marie Curie - Paris 6, Roscoff, France \\ ${ }^{5}$ Laboratoire Adaptation et Diversité en Milieu Marin, CNRS, UMR 7144, Roscoff, France
}

\section{Edited by:}

Kam W. Tang, Virginia Institute of Marine Science, USA

Reviewed by:

Ryan Carnegie, VA Institute of Marine Science, USA

Marja Koski, Technical University of Denmark, Denmark

David McKinnon, Australian Institute of Marine Science, Australia

*Correspondence:

Alf Skovgaard, Laboratory of Aquatic Pathobiology, Department of Veterinary Disease Biology, University of Copenhagen, Stigbejlen 7, DK-1870 Frederiksberg C, Denmark.

e-mail:alf@life.ku.dk
Blastodinium is a genus of dinoflagellates that live as parasites in the gut of marine, planktonic copepods in the World's oceans and coastal waters. The taxonomy, phylogeny, and physiology of the genus have only been explored to a limited degree and, based on recent investigations, we hypothesize that the morphological and genetic diversity within this genus may be considerably larger than presently recognized. To address these issues, we obtained 18S rDNA and ITS gene sequences for Blastodinium specimens of different geographical origins, including representatives of the type species. This genetic information was in some cases complemented with new morphological, ultrastructural, physiological, and ecological data. Because most current knowledge about Blastodinium and its effects on copepod hosts stem from publications more than half a century old, we here summarize and discuss the existing knowledge in relation to the new data generated. Most Blastodinium species possess functional chloroplasts, but the parasitic stage, the trophocyte, has etioplasts and probably a limited photosynthetic activity. Sporocytes and swarmer cells have well-developed plastids and plausibly acquire part of their organic carbon needs through photosynthesis. A few species are nearly colorless with no functional chloroplasts. The photosynthetic species are almost exclusively found in warm, oligotrophic waters, indicating a life strategy that may benefit from copepods as microhabitats for acquiring nutrients in a nutrient-limited environment. As reported in the literature, monophyly of the genus is moderately supported, but the three main groups proposed by Chatton in 1920 are consistent with molecular data. However, we demonstrate an important genetic diversity within the genus and provide evidences for new groups and the presence of cryptic species. Finally, we discuss the current knowledge on the occurrence of Blastodinium spp. and their potential impact on natural copepod populations.

\section{Keywords: Blastodinium, copepod, parasite, symbiont, plankton, ultrastructure, phylogeny}

\section{INTRODUCTION}

The typical dinoflagellate is a motile, bi-flagellated protist, and species of the group may be found in both marine and fresh waters. Roughly half of all dinoflagellates are photosynthetic and half are heterotrophic (Gaines and Elbrächter, 1987). In addition, it has been estimated that approximately $7 \%$ of the dinoflagellates have parasitic life strategies (Drebes, 1984), infecting other protists, cnidarians, crustaceans, fishes, etc. (Coats, 1999) and some of these parasites can be severe pathogens for wild and farmed aquatic organisms. A key morphological feature of the dinoflagellates is their nucleus, the dinokaryon, which differs from the typical eukaryote nucleus by having permanent condensed chromosomes and by lacking histones. However, some of the parasitic dinoflagellates deviate from this typical morphology. In the dinoflagellate order Syndiniales a dinokaryon is never present, and those species that have traditionally been referred to the order Blastodiniales are believed to have a dinokaryon only in some parts of their live cycles. Blastodinium is a genus of dinoflagellates that appears atypical in several aspects. The parasitic stage of Blastodinium exists exclusively inside the gut of marine free-living copepods, where it occupies the lumen of the intestinal tract (Figure 1A). This parasitic stage is multicellular. It consists of several hundred nonflagellated cells, and can reach a length of more than $1 \mathrm{~mm}$. The dispersal stage, the dinospore, of Blastodinium has the morphology of a typical dinoflagellate.

The greater part of our existing knowledge on Blastodinium leads back to the immense work done by the French protozoologist Édouard Chatton (Soyer-Gobillard, 2006) in the first half of the twentieth century, and his 1920 monograph (Chatton, 1920) on the parasitic dinoflagellates is still the primary landmark of several dinoflagellate genera and in particular of the genus Blastodinium. In addition to discovering and describing the 


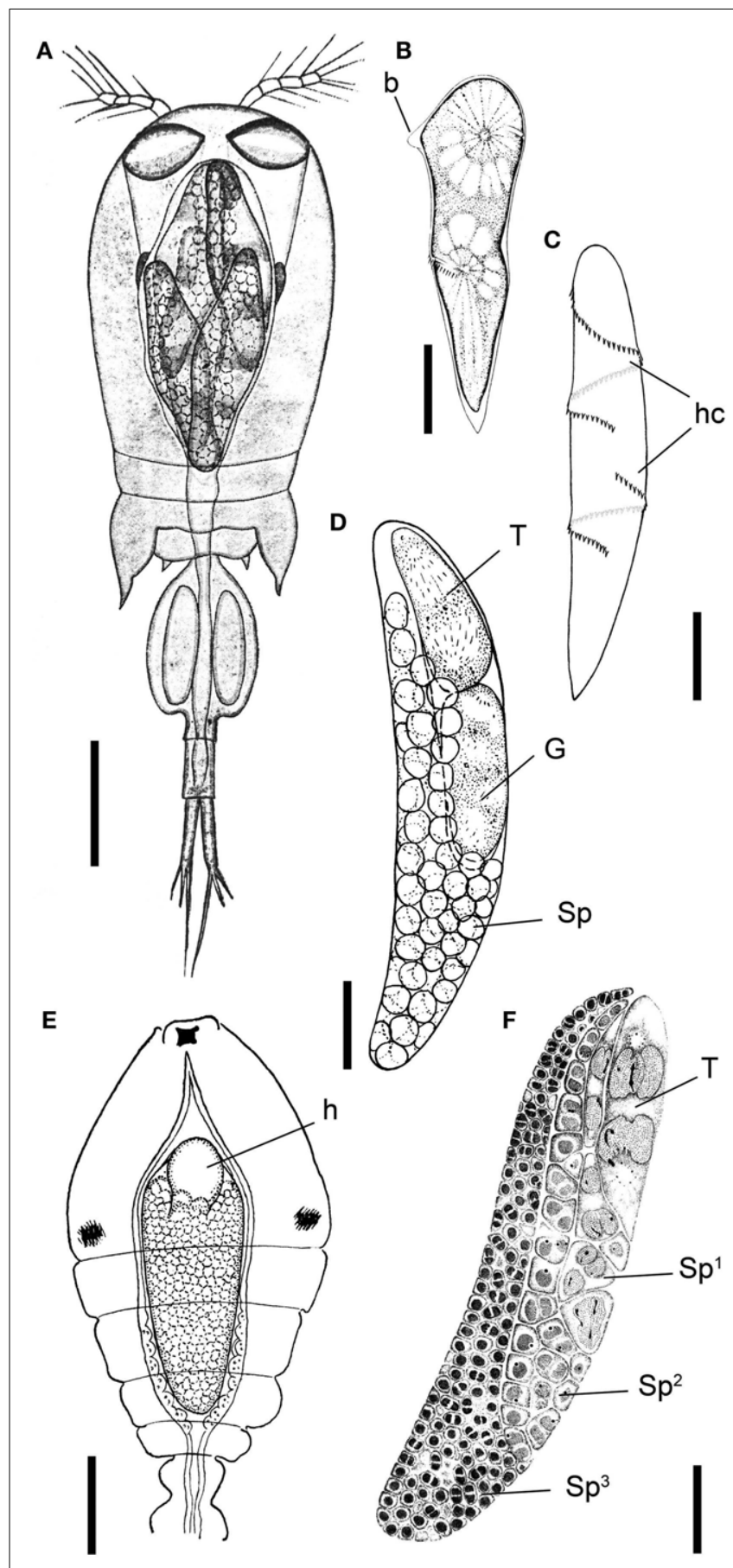

FIGURE 1 | Blastodinium spp. (A) Several B. navicula inside the gut of the copepod Corycaeus giesbrechti. (B) A young trophocyte of B. pruvoti with anterior beak (b). (C) Early stage B. spinulosum with helicoidal crests (hc). (D) B. pruvoti showing trophycyte (T), gonocyte (G), and sporocytes (Sp). (E) B. oviforme with hilum (h) in Oithona nana. (F) B. pruvoti with three progressive layers of sporocytes $\left(\mathrm{Sp}^{1}-\mathrm{Sp}^{3}\right)$. Adapted from Chatton (1920). (A,E) Scale bars $=100 \mu \mathrm{m}$. (B-F) Scale bars $=50 \mu \mathrm{m}$.

genus in 1906, Chatton also described most known Blastodinium species in succeeding publications (Table 1). Since then, only three new species of Blastodinium have been described (Sewell, 1951;
Skovgaard and Salomonsen, 2009), but recent investigations have shown that the genetic diversity within the genus is high, suggesting a larger number of unknown species (Coats et al., 2008; Skovgaard and Salomonsen, 2009; Alves-de-Souza et al., 2011). Investigations of the biology and impact of Blastodinium spp. are remarkably rare considering the large amount of research that is continuously being carried out on the biology and ecology of marine copepods. In this paper we update the current knowledge on the biology, phylogeny, and morphology of Blastodinium spp. and the current reports of distribution and host range of Blastodinium spp. are summarized. The established data is supplemented with new observations on morphology, ultrastructure, molecular phylogeny, and photosynthetic potential of Blastodinium spp. Due to the photosynthetic capability of Blastodinium and the apparently weak pathology associated with the infection, it may be a matter of definition whether members of the genus should be categorized as parasites or symbionts. We here adopt the term parasite because some harmful effect has been documented in association with hosting a Blastodinium.

\section{MATERIALS AND METHODS NEW OBSERVATIONS ON BLASTODINIUM SPP. HOSTS, OCCURRENCE, AND MORPHOLOGY}

Unpublished information on new hosts for Blastodinium spp. in the Atlantic Ocean (including two undescribed species) originate from the field work described in Skovgaard and Salomonsen (2009). Hitherto unpublished scanning electron microscopy (SEM) observations on Blastodinium sp. dinospores were made as part of the study reported by Skovgaard et al. (2007). Most samples for acquisition of new DNA sequences were collected as part of already published studies (Skovgaard and Saiz, 2006; Skovgaard et al., 2007; Skovgaard and Salomonsen, 2009; Alvesde-Souza et al., 2011). Specimens isolates with the prefix "VIL" in Figure 7 are from Villefranche-sur-mer, France. Following samples were collected the 2 of September 2009 at the site "La marinière": VIL4, VIL57, and VIL59 from Farranula rostrata; VIL15, VIL50, and VIL51 from Corycaeus sp.; VIL7 from Triconia sp.; and VIL8 from Corycaeus cf. ovalis. VIL49 from F. rostrata was collected the 3 of September 2009 at "Le plateau." VIL61 from Triconia sp. was collected the 1 of March 2010 at the B site $\left(43^{\circ} 41^{\prime} 10 \mathrm{~N} 7^{\circ} 18^{\prime} 94 \mathrm{E}\right)$. VIL44 from Corycaeus sp. was collected the 9 September 2009 at "La marinière." Isolates with the prefix "GA" were collected in the North Atlantic Ocean.

\section{PHYLOGENETIC ANALYSES}

Blastodinium spp. were dissected from their host and the DNA extracted as described by Alves-de-Souza et al. (2011). Primers for SSU and PCR conditions are also explained in this reference. Primers used to amplify the ITS region were $5^{\prime}$ GTCGCTCCTACCGATTGAGT-3' (name ITS-CER-F) in forward and $5^{\prime}$-CAGACAGGCATGTCACCTTC-3' (name ITS-CER-R) in reverse. PCR conditions were similar to that explained for the SSU. Both SSU and ITS1, 5.8S, and ITS2 amplicons were cloned and sequenced as following the procedure by Alves-de-Souza et al. (2011), and consensus sequences were deduced from the analysis of three different clones. SSU and ITS alignments were 
Table 1 | Recognized species of Blastodinium and their reported copepod hosts.

\begin{tabular}{lll}
\hline Parasite & Hosts & Reference \\
(Author, year) & &
\end{tabular}

\section{Spinulosum} group

B. spinulosum

(Chatton, 1908)

\section{Calanoida, Cyclopoida,} Poecilostomatoida

Acrocalanus gracilis Giesbrecht 2 Clausocalanus arcuicornis Dana 1

C. furcatus Brady

C. farrani Sewell

Paracalanus aculeatus Giesbrecht

$P$. denudatus Sewell 2

P. parvus Claus

B. pruvoti (Chatton, Clausocalanus arcuicornis

1906)

B. crassum

(Chatton, 1908)

B. inornatum
(Chatton, 1920)
B. oviforme
(Chatton, 1912)

Contortum group

B. contortum

(Chatton, 1908)

\section{C. furcatus}

Nannocalanus minor Claus

Paracalanus parvus

Paracalanus parvus

P. nanus Sars

Calocalanus styliremis Giesbrecht

Clausocalanus arcuicornis

C. furcatus

P. aculeatus

Clausocalanus arcuicornis

C. furcatus

Paracalanus parvus

Corycaeus crassiusculus Dana

C. speciosus Dana

Farranula gibbula Giesbrecht

Oithona similis Claus

O. nana Giesbrecht

O. plumifera Baird

Oncaea media Giesbrecht

O. venusta Philippi

Triconia conifera Giesbrecht

\section{Calanoida}

Acartia clausi Giesbrecht

Acrocalanus gracilis

1

2

2

2

2
Calocalanus styliremis

Clausocalanus arcuicornis

C. furcatus

C. lividus Frost \& Fleminger

Cosmocalanus darwini Lubbock

Eucheata indica Wolfenden

Nannocalanus minor

Paracalanus aculeatus

$P$. denudatus

P. parvus

Subeucalanus pileatus Giesbrecht

S. subtenuis Giesbrecht

Temora stylifera Dana

B. hyalinum

Acartia clausi

Calanus finmarchicus Gunnerus

Parasite
(Author, year)

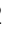

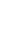

$2^{+}$

$2^{+}$

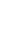

2

1

(1)

B. mangini var.

oncaea (Chatton,

1912)

B. navicula

(Chatton, 1912)

B. elongatum

(Chatton, 1912)

B. galatheanum

Skovgaard

Blastodinium spp.

Blastodinium sp. $\alpha$

Blastodinium sp. $\beta$

Blastodinium sp. $\gamma$

Blastodinium sp. $\delta$

Blastodinium spp.

$5 ?$

Figures 11E,F

$4 / 1$

$4 / 1$
Hosts

Reference

Centropages sp.

Clausocalanus arcuicornis

1

C. furcatus

$4 / 1$

Paracalanus aculeatus $\quad 1$

P. denudatus 2

P. parvus 2

Paracalanus sp. $\quad 1$

Paraeuchaeta antarctica Giesbrecht 4/1

Pseudocalanus elongatus Boeck 6?

Pseudocalanus sp. 2

Clausocalanus arcuicornis $\quad 1 / 2$

C. furcatus 2

Paracalanus aculeatus 2

Clausocalanus arcuicornis 2

C. furcatus 2

Cosmocalanus darwini 2

Eucheata indica Wolfenden 2

Nannocalanus minor 2

Paracalanus aculeatus 2

P. denudatus 2

P. parvus 2

Poecilostomatoida, Calanoida

Farranula gibbula Giesbrecht $\quad 2^{\#}$

F. rostrata Claus $1^{*}$

Oncaea media Giesbrecht $\quad 2^{\#}$

O. venusta Philippi $2^{\#}$

Oncaea cf. scottodicarloi Heron \& $\quad 7^{\#}$

Bradford-Grieve

Triconia conifera Giesbrecht $\quad 2^{\#}$

F. rostrata 1

O. media $\quad 1^{*}$

Triconia minuta Giesbrecht $\quad 1$

Corycaeus giesbrechti Dahl $\quad 1$

O. venusta $2 *$

Centropages sp. 1

Scolecithrix bradyi Giesbrecht $\quad 1$

Acartia negligens Dana 8

Acartia sp. 8

Temora stylifera

Clausocalanus furcatus 1

C. arcuicornis 1

Paracalanus parvus 1

Corycaeus giesbrechti 1

Acrocalanus longicornis Giesbrecht 5

Aetidius giesbrechti Cleve 3

Centropages typicus Krøyer 3

Clausocalanus furcatus 3

C. parapergens Frost \& Fleminger $\quad 10$ 
Table 1 | Continued

\begin{tabular}{|c|c|c|}
\hline \multicolumn{3}{|l|}{ (Author, year) } \\
\hline & Corycaeus flaccus Giesbrecht & 3 \\
\hline & C. typicus Krøyer & 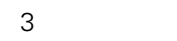 \\
\hline & Euchaeta rimana Bradford & 5 \\
\hline & Farranula carinata Giesbrecht & 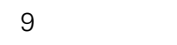 \\
\hline & Nannocalanus minor & 3 \\
\hline & Neocalanus robustior Giesbrecht & 5 \\
\hline & Pareucalanus sewelli Fleminger & 5 \\
\hline & Pleuromamma gracilis Claus & 3 \\
\hline Blastodinium sp. I & Euchaeta sp. & Figures $6 A, B$ \\
\hline Blastodinium sp. II & Euchaeta sp. & Figures $6 C, D$ \\
\hline \multicolumn{3}{|c|}{ *The genera Oncaea and Triconia have been thoroughly revised since the work of } \\
\hline \multicolumn{3}{|c|}{ Chatton (1920) and Sewell (1951) signifying that these early observations proba- } \\
\hline \multicolumn{3}{|c|}{ bly included several at that time unrecognized host species. } \\
\hline \multicolumn{3}{|c|}{${ }^{+}$No distinction was made between B. crassum and B. inornatum. } \\
\hline \multicolumn{3}{|c|}{${ }^{\#}$ No distinction was made between B. mangini and B. mangini var. oncaea. } \\
\hline \multirow{2}{*}{\multicolumn{3}{|c|}{$\begin{array}{l}\text { A question mark indicates that the parasite species was identified tentatively by } \\
\text { the authors. }\end{array}$}} \\
\hline & & \\
\hline \multirow{5}{*}{\multicolumn{3}{|c|}{$\begin{array}{l}\text { 1, Summarized by Chatton (1920); 2, Sewell (1951); 1/2, Reported by Chatton } \\
\text { (1920) and parasite subsequently identified by Sewell (1951); 3, lanora et al. } \\
\text { (1990); 4/1, Reported by Apstein (1911) and parasites subsequently identified } \\
\text { by Chatton (1920); 5, Pasternak et al. (1984); 6, Oresland (1991); 7, Skovgaard } \\
\text { (2005); 8, Skovgaard and Salomonsen (2009); 9, Drits and Semenova (1985); 10, } \\
\text { Alves-de-Souza et al. (2011). }\end{array}$}} \\
\hline & & \\
\hline & & \\
\hline & & \\
\hline & & \\
\hline \multicolumn{3}{|c|}{ Species names were validated according to Razouls et al. (2005-2012). } \\
\hline
\end{tabular}

obtained using the online version of MAFFT ${ }^{1}$. ITS alignment was secondarily manually optimized using secondary structures using models described by Gottschling and Plötner (2004). Noninformative sites were removed using Gblocks ${ }^{2}$. A Bayesian phylogenetic tree was constructed with MrBayes v3.2 (Huelsenbeck and Ronquist, 2001) using a GTR substitution model with gammadistributed rate variation across sites $(\mathrm{GTR}+\mathrm{I})$ as suggested as the best-fit model in MrModelstest v2.3 (Nylander, 2004). Four simultaneous Monte Carlo Markov chains were run from random trees for a total of 1,000,000 generations in two parallel runs. A tree was sampled every 100 generations, and a total of 2,500 trees were discarded as 'burn-in' upon checking for stationarity by examination the log-likelihood curves over generations, and posterior probabilities were calculated in MrBayes. A consensus tree (50\% majority rule) was constructed from the post-burn-in trees and posterior probabilities were calculated in MrBayes.

\section{TRANSMISSION ELECTRON MICROSCOPY}

For transmission electron microscopy (TEM) the intact copepods, Faranulla rostrata, with parasites were fixed by two methods: (1) $1.5 \mathrm{ml}$ of $2.5 \%$ glutaraldehyde on $0.05 \mathrm{M}$ cacodylate buffer $(\mathrm{pH}$ 7.4) diluted from $0.2 \mathrm{M}$ on marine water were mixed with $0.5 \mathrm{ml}$ of $4 \% \mathrm{OsO}_{4}$ and added to the sample for $35 \mathrm{~min}$ in the dark. Thus, the final concentrations of glutaraldehyde and $\mathrm{OsO}_{4}$ were

\footnotetext{
${ }^{1}$ http://mafft.cbrc.jp/alignment/server/

${ }^{2}$ http://molevol.cmima.csic.es/castresana/Gblocks_server.html
}

1.9 and $1 \%$ correspondingly. (2) $0.5 \mathrm{ml}$ of $2.5 \%$ glutaraldehyde on $0.05 \mathrm{M}$ cacodylate buffer ( $\mathrm{pH}$ 7.4) diluted from $0.2 \mathrm{M}$ on marine water were mixed with $0.5 \mathrm{ml}$ of $4 \% \mathrm{OsO}_{4}$ and added to the sample for $40 \mathrm{~min}$ in the dark (final concentrations of glutaraldehyde and $\mathrm{OsO}_{4}$ were 1 and $2 \%$ correspondingly). The dehydration with alcohol series from 30 to $70 \%$ followed without rinsing. All steps of fixation and the dehydration were on ice. The material was kept in $70 \%$ alcohol in the freezer $\left(-20^{\circ} \mathrm{C}\right)$ for a week before the consecutive dehydration and embedding in Epon. The ultrathin sections were prepared using a ultra-microtome Leica ultracut UCT (Leica Microsystems, Germany), stained with uranyl acetate and lead citrate, and viewed in a JEOL JEM 1400 transmission electron microscope (JEOL Ltd., Japan) at $80 \mathrm{kV}$, equipped with digital camera Orius SC1000 (Gatan Inc., USA).

\section{PHOTOSYNTHESIS}

Photosynthetic rates, $\mathrm{P}$, were measured by the modified single cell technique as described by Skovgaard et al. (2000). Copepods were collected in the NW Mediterranean Sea in November, 2003 (Skovgaard and Saiz, 2006) and used for experiments within the same day. All handling and incubation was done at a temperature corresponding to that of the site of collection $\left(16.2^{\circ} \mathrm{C}\right)$. Prior to incubation, copepods (Oncaea spp.) were gently picked out individually and rinsed in $0.2-\mu \mathrm{m}$ filtered, freshly collected seawater. For incubation, copepods were transferred to $20 \mathrm{ml}$ capacity glass scintillation vials containing $2 \mathrm{ml} 0.2-\mu \mathrm{m}$-filtered seawater. Each vial contained two copepods infected with Blastodinium sp. (presumably B. mangini). $\mathrm{A} \mathrm{NaH}^{14} \mathrm{CO}_{3}$ stock solution was added (specific activity $=100 \mu \mathrm{Ci} \mathrm{ml}^{-1}$, Carbon 14 Centralen, DHI-Group, Denmark), resulting in a specific activity of approximately $0.9 \mu \mathrm{Ci} \mathrm{ml}^{-1}$. Vials were then incubated for $4 \mathrm{~h}$ in triplicates at irradiances of $50,150,250$, and $350 \mu \mathrm{mol}$ photons $\mathrm{m}^{-2} \mathrm{~s}^{-1}$ plus a triplicate that was incubated in the dark. After incubation, specific radioactivity of the medium was checked after incubation by transferring $100 \mu \mathrm{l}$ incubation water from each vial to new vials containing $200 \mu \mathrm{l} \mathrm{NaOH}$. The amount of fixed ${ }^{14} \mathrm{C}$ was measured in the remaining $1.9 \mathrm{ml}$, which received $2.0 \mathrm{ml}$ of $10 \%$ glacial acetic acid in methanol to remove all inorganic $\mathrm{C}$. Vials were dried overnight at $60^{\circ} \mathrm{C}$ whereupon residues were re-dissolved in $2 \mathrm{ml}$ distilled water and $10 \mathrm{ml}$ of Packard Insta-Gel Plus scintillation cocktail (PerkinElmer, USA) were added to all vials. Finally, new caps (Packard poly screw caps, PerkinElmer) were mounted and activities were determined with a Packard 1500 Tri-Carb liquid scintillation analyzer (PerkinElmer). Calculations of photosynthetic rates, $\mathrm{P}$, were based on the equation given by Parsons et al. (1984).

\section{RESULTS AND DISCUSSION LIFE CYCLE STAGES AND THEIR MORPHOLOGY Life cycle}

The complete life cycle of Blastodinium has not been demonstrated definitively, but the morphology of distinct stages of the parasite cycle has been described. According to Chatton (1920), the infection cycle of Blastodinium starts with the ingestion of a dinospore by a copepod and, instead of becoming digested, the dinospore grows in size and develops into a trophocyte, which is the earliest parasitic phase that has been identified. In young trophocytes that 
have recently infected their host, an anterior beak may sometimes be present (Figure 1B).

Following infection, the trophocyte produces the characteristic large multicellular structure (Figure 1), which corresponds to the parasite undergoing palisporogenetic divisions. Thus, the trophocyte divides into a secondary trophocyte and a gonocyte contained within a common cuticle (Figure 1D). This external cuticle of the sporogenetic individual was described by Chatton (1920) to be formed by the delamination of the mother trophocyte membrane (Figures 2-4). In comparison with the unitary membrane, this cuticle is much thicker, about $15-20 \mathrm{~nm}$ (Figure 4B) vs. the thickness of $7-8 \mathrm{~nm}$ of the unitary membrane. The cuticle has a three-layered structure: an electron dense inner, a translucent middle, and a comparatively dense outer layer (Figure 4B). None

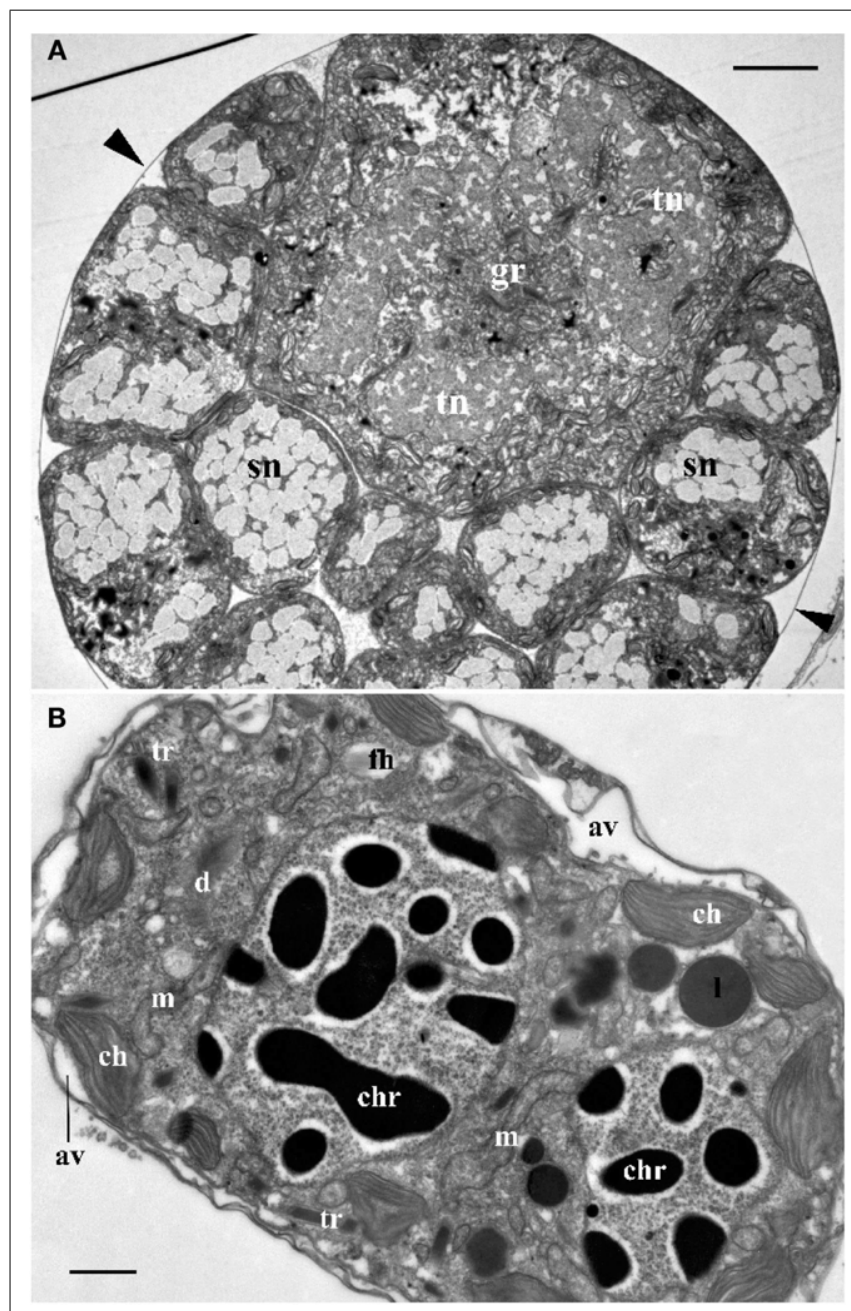

FIGURE 2 | (A) Cross section through the central part of Blastodinium cf. mangini (from Farranula rostrata) showing a big trophocyte with several layers of sporocytes covered by common a cuticle (arrowheads). gr, golgi region; sn, nucleus of sporocyte; tn, nucleus of trophocyte. Scale bar $=5 \mu \mathrm{m}$. (B) Ultrastructure of mature Blastodinium cf. navicula sporocyte (from F. rostrata). av, amphiesmal vesicle (alveolus); ch, chloroplast; chr, chromosome; cu, cuticle; $d$, dictyosome; fh, vesicle with future flagellar hairs; I, lipid droplet; m, mitochondrion; tr, trichocyst. Scale bar $=1 \mu \mathrm{m}$. of these three layers has a typical membrane structure. Thus, the cuticle can be considered an extracellular envelope. When stained with Calcofluor White (which stains dinoflagellate thecal plates; Fritz and Triemer, 1985), it is the covering of the underlying cells that is stained rather than the cuticle (Figures 5A,B). After the initial division of the trophocyte, the produced gonocyte will divide into a large number of sporocytes still retained within the external cuticle, resulting in a large multicellular individual (Chatton, 1920; Figures 1 and 5A,B). In some cases (to some extent species dependent) the secondary trophocyte will divide into a tertiary trophocyte, and a new gonocyte will then produce a second layer of sporocytes (Figure 1F). This process may be repeated and result in several layers of sporocytes. Chatton (1920) referred to these conditions as mono-, di-, or polyblastic, dependent on how many layers of sporocytes were surrounding the trophocyte. In some species, the trophocyte is not completely embedded by sporocytes, leaving a "naked" area, a hilum (Figures 1E and 2A), where the trophocyte is visible and in direct contact with the cuticle.

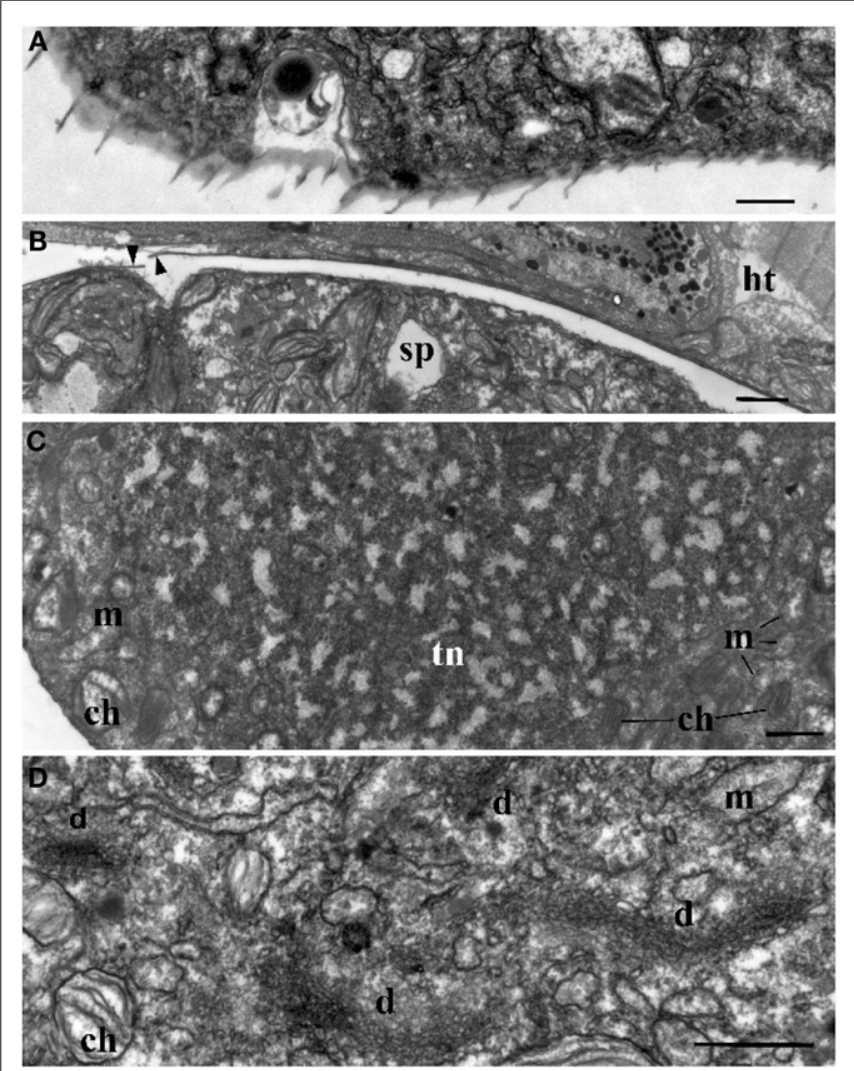

FIGURE 3 | Ultrastructure of Blastodinium. (A) Cell covering of Blastodinium cf. mangini (from Farranula rostrata) in crest region. (B) Cuticle of trophont attached tightly to the gut tissue of the host (ht); arrowheads show broken cuticle on the left. Blastodinium cf. mangini (from F. rostrata). (C) Portion of trophocyte of Blastodinium cf. navicula sporocyte (from F. rostrata) with huge nucleus (tn) containing decondensed chromosomes (light zones) and granular material (possibly ribosomal subunits), small chloroplasts (ch) and mitochondria (m). (D) Golgi region of trophocyte of $B$. cf. mangini (from F. rostrata) with prominent dictyosomes (d), chloroplasts (ch), and mitochondria (m). Scale bar $=1 \mu \mathrm{m}$. 


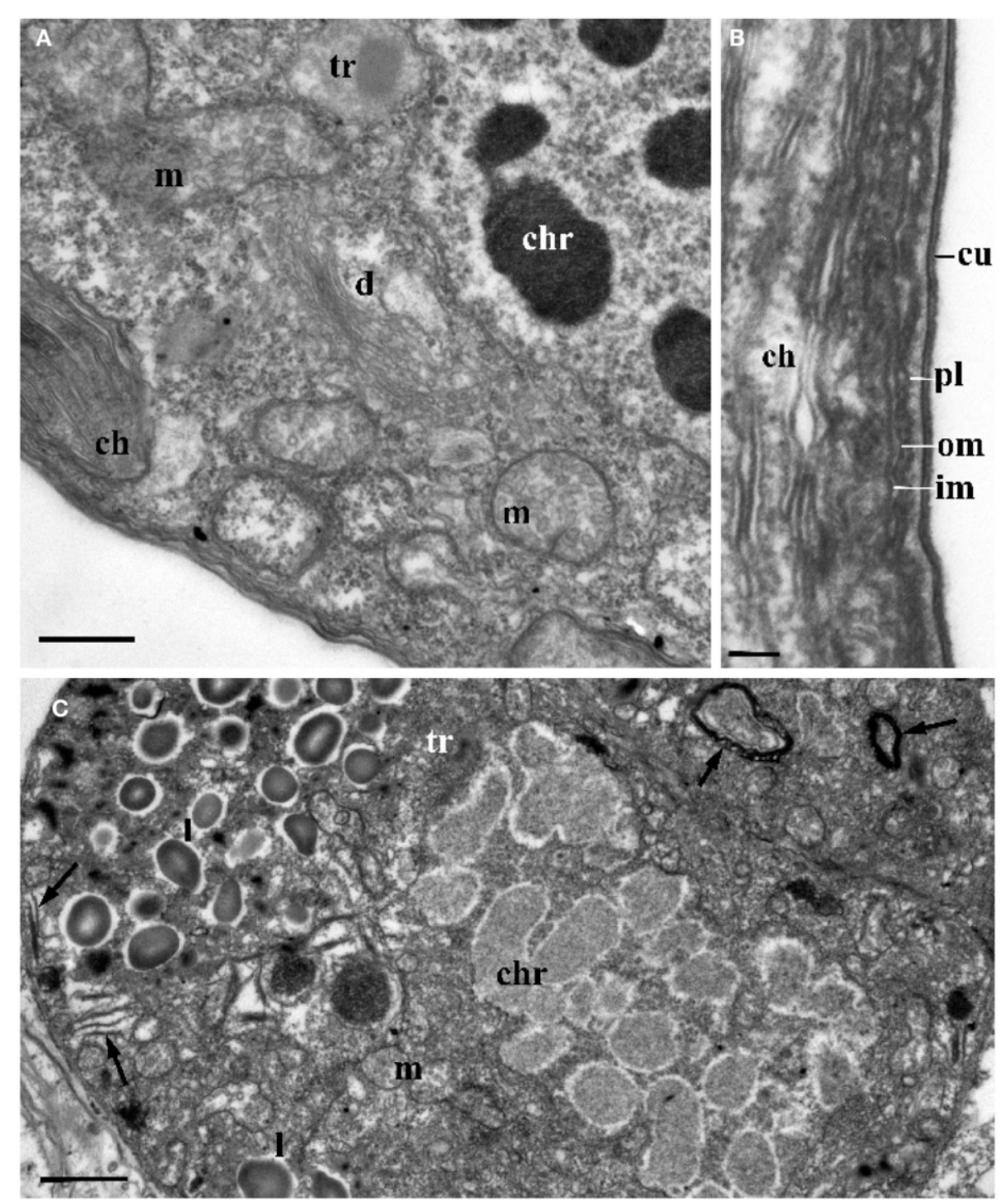

FIGURE 4 | The ultrastructure of Blastodinium sporocyte. (A) Portion of nucleus and cytoplasm of Blastodinium cf. navicula sporocyte (from $F$. rostrata). (B) Structure of coverings of Blastodinium cf. navicula sporocyte (from F. rostrata). (C) Colorless representative of Blastodinium (Blastodinium cf. hyalinum from Paracalanus parvus). ch, chloroplast; chr, chromosome; cu, cuticle; d, dictyosome; im, inner and outer (om) membrane of alveoli; I, lipid droplets; m, mitochondrion; pl, plasma membrane; tr, maturing trichocyst. Arrows show reduced presumed plastids. (A) Scale bar $=2.5 \mu \mathrm{m}$. (B) Scale bar $=0.1 \mu \mathrm{m}$. (C) Scale bar $=1 \mu \mathrm{m}$.
Sporulating individuals generally measure up to several hundreds of $\mu \mathrm{m}$ in length and are often detected coincidentally inside the transparent copepod's gut thanks to their size and the brownish to greenish color caused by the presence of chloroplasts. The rupture of the cuticle leads to the release of sporocytes into the water through the copepod anus.

The surface of the parasite cuticle is at times ornamented with two helical rows of minute spinules along the body (Figure 1C). These "helicoidal crests" can be difficult to discern in the light microscopy, but are readily seen in SEM (Skovgaard and Salomonsen, 2009) and in ultrathin sections (Figure 3A). They are formed by papillae located on the trophocyte (see Figure XXVII, p. 132, in Chatton, 1920). The crests may also be visualized by hematoxylin-staining (Coats et al., 2008). The crests are not one continuous helix, but formed by two distinct sections. This reflects the fact that the trophozoite is composed of "Siamese twins," each of them having their own nucleus (Chatton, 1920). This dualism is also conserved in sporocytes (Figure 2B). Blastodinium spp. do not possess a peduncle or other holdfast organelles (Fensome et al., 1993), but one may speculate that the anterior beak of young trophocytes and/or the spinules of the helicoidal crests may play a role in anchoring the parasite to the copepod gut lining. In addition, sections made on infected copepods show that sporulating Blastodinium appear attached to the gut epithelium, and the outer covering has a tight contact with epithelium (Figure 3B). 

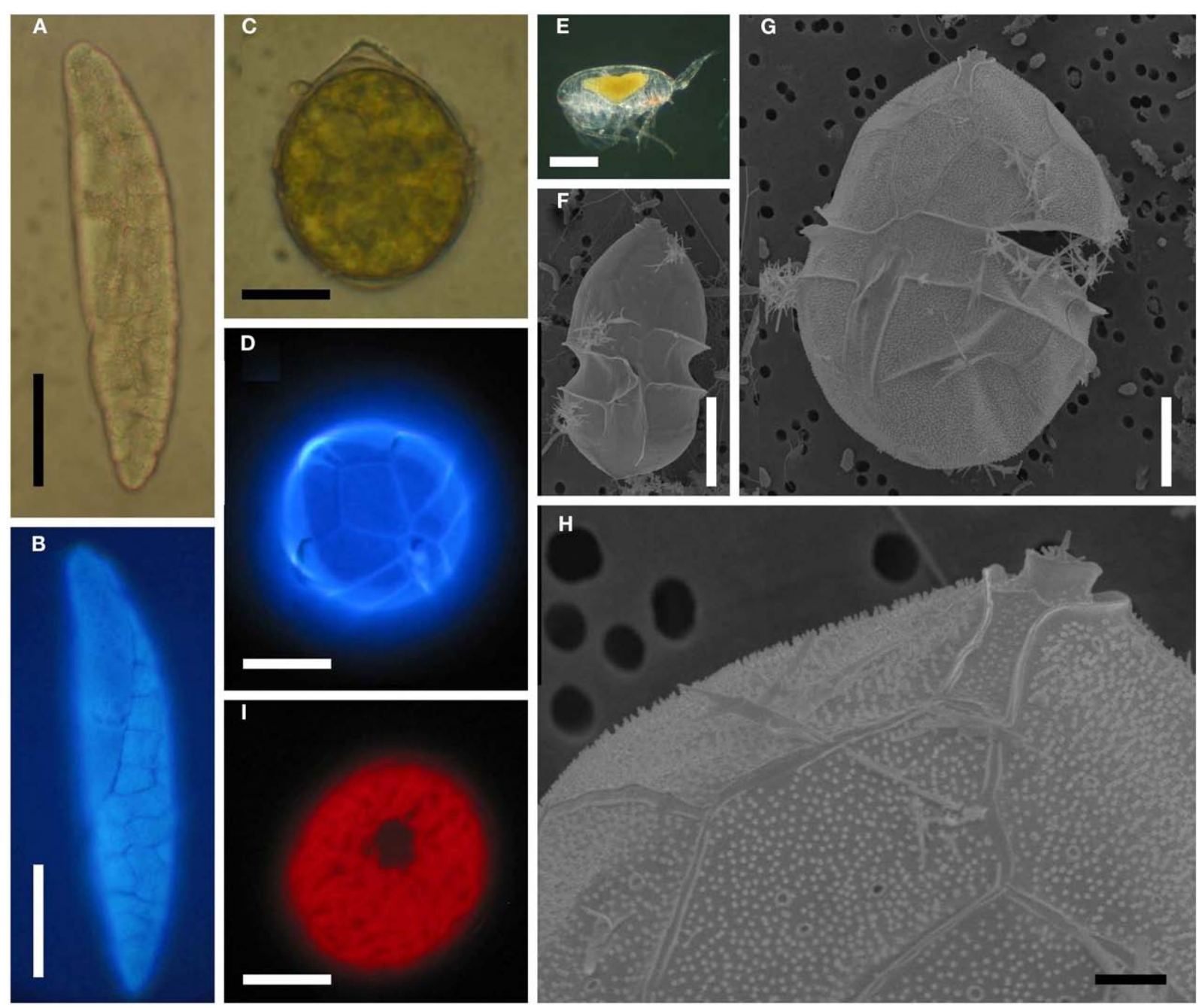

FIGURE 5 | Blastodinium spp. (A) B. mangini from Oncaea sp. (B) Same as (A) but stained with Calcofluor White. (C) B. oviforme dinospore from 0 . similis. (D) Same as (C) but stained with Calcuflour White. (E) Clausocalanus $\mathrm{sp}$. infected with Blastodinium sp. (F) B. contortum dinospore, SEM. (F) B. contortum dinospore, SEM. (G,H) Dinospore from the parasite in (E), SEM. (I) Blastodinium sp. dinospore showing autofluorescence of chloroplasts viewed in epifluorescent light. (A,B) Scale bar $=50 \mu \mathrm{m}$. (C,D,I) Scale bars $=10 \mu \mathrm{m}$. (E) Scale bar $=200 \mu \mathrm{m}$. (F,G) Scale bars $=5 \mu \mathrm{m}$. (H) Scale bar $=1 \mu \mathrm{m}$.
Some Blastodinium species are gregarious, i.e., several individuals of the same parasite are present in one host individual. Such gregarious parasites are thought be the result of a division of the trophocyte by binary fission into two daughter trophocytes (either before or during sporogenesis). Chatton (1920) used the term "endogenous multiplication" for this type of division compared to the sporogenesis that was referred as "exogenous multiplication" or "palisporogenesis." During endogenous multiplication the two daughter trophocytes are each surrounding by a new cuticle, and they will eventually produce independent, but synchronous, generations of sporocytes. Rupture of the original cuticle will then release two daughter parasites of approximately similar size. Conversely, the infection with one Blastodinium species appears to prevent succeeding infections (Chatton, 1920). Multiple individuals in a single host are, thus, typically of approximately similar developmental stage. However, this is not always the case, and Sewell (1951) consequently suggested that successive infections of a single host may also be possible. The final proof of multiple infections would be the presence of two different Blastodinium species in a single host, but this has never been observed.

\section{The dinospore}

Sporocytes released through the copepods anus are initially nonmotile. After few hours, these bi-nucleated cells acquire flagella and divide into four uni-nucleate dinospores (Chatton, 1920; Soyer, 1971; Figure 5C). These dinospores are thecate with plates that are clearly visible when stained with Calcofluor White (Figure 5D) as well as in SEM (Figures 5F-H). The pattern and arrangement of thecal plates on Blastodinium dinospores is typical for Peridiniales. A pattern of pores encircled by each a single ring gives some resemblance to the peridinoid dinoflagellate genus Pentapharsodinium (Skovgaard et al., 2007) on which thecal plates are ornamented with one or two concentric rings. With respect of the thecal tabulation pattern, no distinct differences have been found between 
the morphology of the species B. navicula, B. contortum, and $B$. galatheanum (Skovgaard et al., 2007; Skovgaard and Salomonsen, 2009). However, variation in the morphology of Blastodinium dinospores does occur. The cell depicted in Figure 5G is considerably larger than the typical dinospore (Figure 5F). Even though the plate tabulation pattern is similar in both types of dinospores, the larger dinospore has a distinctive theca possessing a dense coverage of papillae (Figures $\mathbf{5 G}, \mathbf{H}$ ). These unusual dinospores were collected after having been expelled from Blastodinium sp. hosted by a single specimen of Clausocalanus sp. (Figure 5E) and they were motile at the time of fixation. Thus the aberrant morphology of these dinospores cannot presently be explained, but it is probable that they represent a species yet not described.

\section{Infection and transmission}

While it appears logical that Blastodinium infects its host through oral transmission by a dinospore, the means of infection has never been proved experimentally. Likewise, the mechanism by which the infective dinospore is subsequently able to avoid digestion and remain in the gut of its host is currently unknown. Attempts to transmit Blastodinium experimentally from infected copepods to uninfected individuals have been unsuccessful (Chatton, 1920; Skovgaard, 2005). It has been suggested that adult copepods are not infected, but that infection takes place in the juvenile stages (Chatton, 1920; Alves-de-Souza et al., 2011). This theory might explain the failure of transmission experiments, since these have concentrated on late copepodite stages and adult copepods.

\section{ULTRASTRUCTURAL MODIFICATIONS DURING SPOROGENESIS}

The Blastodinium trophocyte has an aberrant morphology compared to typical dinoflagellates, which is plausibly a result of its parasitic life style. Following successive sporogenetic generations, cells are gradually re-acquiring typical features of free-living dinoflagellates. These morphological transformations can be observed in a single polyblastic individual, since such individual will have different layers of sporocytes of different age (Soyer, 1970, 1971).

\section{Nucleus}

Ultrastructure of the nucleus during mitotic divisions was studied in detail by Soyer (1971). According to that report and Figures 2-4, Blastodinium has a dinokaryotic nucleus at all stages with the nuclear envelope remaining intact during mitosis and chromosomes staying attached to the inner membrane. Invaginations of the nuclear envelope with cytoplasmic microtubules inside are also frequently observed, demonstrating typical dinomitosis. However, although the trophocyte nucleus has dinokaryotic chromosomes (lacking histones), these are decondensed with a large amount of granular contents (ribosomal subunits) around (Figures 2A and 3C). Progressive condensation of chromosomes takes place during sporogenesis (Soyer, 1971). The first sporocyte layers have nuclei with less nucleoplasm and much more condensed chromosomes. They will remain in such condition during several sporogenetic divisions (Figures $\mathbf{2 A}$ and $\mathbf{4 A}, \mathrm{C}$ ). The most condensed chromosomes appear in the mature sporocytes (Figure 2B) and this chromosome compaction is concomitant to the reduction of nuclear size.

\section{Chloroplasts}

Plastids of the trophocyte are rather small, often with light stroma and few thylacoids (like etioplastids in plants; Soyer, 1970; Figures 2A and 3C,D). However, they are fully reactivated during the course of sporogenesis and in mature sporocytes the plastids are well developed and located at the cell periphery (Figure 2B). Pyrenoids are present in later stage only (Figures $\mathbf{2 B}$ and $\mathbf{4 A}$ ). The colorless species B. hyalinum seems to possess remnants of chloroplasts, but these are very rare and appear to be highly degenerated (Soyer, 1970; Figure 4C).

\section{Trichocysts}

Blastodinium has typical dinoflagellate trichocysts that are very rare, if present at all, in the trophocyte (Figure 3). Some premature stages of trichocyst development are found in immature sporocytes (Figure 4), and many well-developed trichocysts are present in mature, binucleate sporocytes (Figure 2B).

\section{Golgi apparatus}

Soyer (1970) also reported additional transformations in the Golgi apparatus and mitochondria along the sporogenetic process. These observations are not confirmed here in sections of B. mangini, but Figures 2 and 3D show that the Golgi apparatus was extremely large in the trophocyte, composed of several huge dictyosomes, some of them up to $5 \mu \mathrm{m}$ in length. It occupies a big region between the two nuclei of the trophocyte (Chatton, 1920; Figures 2 and 3D). Both the nuclear structure and the Golgi structure reveal the intense metabolic activity of the trophocyte stage. In addition, mitochondria were well developed at all stages of Blastodinium proliferation having typical dinoflagellate tubular cristae (Figures 3 and 4).

\section{Cell covering}

Membrane structures surrounding the trophocyte and sporocytes are of similar appearance, being covered by three membranes corresponding to the typical dinoflagellate amphiesma (Figure 4). The alveoli are flat with electron translucent contents. The outer membranes of the alveoli attach tightly to the plasma membrane. However, this amphiesma becomes more elaborate in mature sporocytes, with broader alveoli (Figure 2B). In conclusion, a mature sporocyte with two nuclei has very condensed chromosomes, developed amphiesma, mature trichocysts, and prominent chloroplasts (Figure 2B), which seem to represent typical features of naked immature dinospores.

\section{TAXONOMY}

\section{Taxonomic position of the genus}

Since the discovery of Blastodinium, it has been recognized that these organisms exhibit features that separate them from the bulk of the dinoflagellates of the class Dinophyceae. Blastodinium has thus been appointed as the type genus of a separate class, the Blastodiniphyceae (Fensome et al., 1993), comprising the single order Blastodiniales. Blastodiniphyceae was synonymized with Haplozooidea and placed in the superclass Hemidinia by Cavalier-Smith (1993). The main character distinguishing the class from the Dinophyceae has been a parasitic life mode and the presence of histones in larger trophic cells and the absence of such in the smaller swarmers (dinospores), i.e., a temporary dinokaryon (Fensome et al., 
1993). Recent findings that Blastodinium dinospores are thecate with a thecal plate tabulation pattern corresponding to that of Peridinian dinoflagellates (Skovgaard et al., 2007) suggest a closer relationship with the Dinophyceae and this is also supported by molecular phylogeny.

\section{Species distinction}

The main characters for species discrimination within the genus Blastodinium are based upon morphological distinctions of the parasitic stage (Chatton, 1920), such as size, the location of the trophocyte, coloration, number of sporocyte layers, the presence of a hilum, and the existence of helicoidal crests. Another important character is whether the parasites are solitary or gregarious in their hosts. Among the gregarious species, also the number of parasites in each host is given taxonomic importance. Gregarious species typically have 2, 3, or 4 parasites in each host, but some species, such as B. spinulosum, are often more numerous; more than 10 is not unusual and up to 23 parasites have been found in a single B. spinulosum in Paracalanus parvus (Chatton, 1920). Based on these morphological characters, Chatton (1920) arranged Blastodinium spp. in three groups, the spinulosum group, the contortum group (in which the two species described by Sewell also fit), and the mangini group (Table 1). The main characteristics of the spinulosum group are that the parasites are curved and shaped like a small boat with a rounded anterior pole and a pointed posterior pole, the trophocyte is located in the anterior part, and the parasite body is traversed by a groove and one or more helicoidal crest(s). The contortum group is characterized by the parasite body being twisted in early developmental stages, they have no helicoidal crest, no groove, and they are usually solitary in their host. In the mangini group, both poles of the parasite are rounded and individuals are nearly straight. Finally, the host species, or the range of host species, is of taxonomic importance.

There are currently 13 accepted species of Blastodinium (Table 1), of which the majority were discovered in copepods from the Mediterranean Sea early in the twentieth century (Chatton, $1906,1908,1911,1912,1920)$. Two taxa were originally described as varieties (B. crassum var. inornatum and B. contortum var. hyalinum; Chatton, 1920) but these have subsequently been generally accepted as independent species, i.e., B. crassum and B. hyalinum. A couple of species were afterward found in the Arabian Sea and described by Sewell (1951). Since then only a single new species has been identified and described, namely B. galatheanum (Skovgaard and Salomonsen, 2009). B. hyalinum is the only species that was explicitly described as being colorless (Chatton, 1911). However, the two species named by Sewell (1951), B. apsteini and B. chattoni, were noted as having closest similarity to $B$. hyalinum, so even though the pigmentation was not mentioned in the description of these two species, one must assume that they were considered to be colorless.

\section{Unrecognized morphological diversity}

Limited work has been done on the taxonomy of Blastodinium since the work by Chatton and Sewell, and studies of Blastodinium outside European waters are still few. It is, therefore, possible that the diversity within this genus is not yet fully elucidated, and indeed several morphotypes have been observed which cannot be assigned to any known species (Table 1). A study on Blastodinium in the Mediterranean Sea revealed several specimens with a morphology that did not match any described species (Alves-de-Souza et al., 2011). The isolate BOUM7 in that study was not only morphologically different from any known Blastodinium species; it was also genetically distinct from other members of the genus. Furthermore, during a recent 2-weeks cruise in warm, oligotrophic waters of the central Atlantic Ocean from the Azores Islands to the Southern coast of West Africa, a new Blastodinium species was found and described (Skovgaard and Salomonsen, 2009) and a couple of specimens of each two other unknown Blastodinium specimen were observed (Figure 6). One of these was a large species ( $>1 \mathrm{~mm}$ long) with six conspicuously colored parasites in a single host individual, Euchaeta sp. (Figures 6A,B); the other one a solitary likewise colored specimen in the same host species (Figures 6C,D). The ease by which these unknown members of Blastodinium were found reinforces perceptions that the morphological diversity of the genus is presently being underestimated. In fact, scientists tend not to assign species names to individual organisms when studying Blastodinium spp. (Pasternak et al., 1984; Ianora et al., 1990; Øresland, 1991), which probably reflects the high morphological variation within the genus resulting in many morphotypes that appear intermediate between recognized species.

\section{PHYLOGENY}

\section{Phylogenetic position of the genus}

The temporary dinokaryon has been considered the phylogenetically important character distinguishing the Blastodiniphyceae from the typical dinoflagellates, the Dinophyceae (Saunders et al., 1997), and the Blastodiniphyceae have been considered evolutionary basal to the Dinophyceae. The importance of the temporary dinokaryon as a taxonomic feature has, however, been questioned (Fensome et al., 1993) and its phylogenetic value may also be limited. Furthermore, molecular phylogenetic studies have shown that species originally classified in the Blastodiniphyceae are polyphyletic and have placed several blastodinian dinoflagellate species well within the Dinophyceae (Saldarriaga et al., 2004). Hence, differences in nuclear structure are of dubious phylogenetic significance.

Traditional dinoflagellate morphology-based taxonomy does not always conform to modern taxonomy in which molecular phylogeny is taken into account (Fensome et al., 1999; Saldarriaga et al., 2004) and the phylogeny of dinoflagellates has been emended considerably after molecular phylogeny has been widely incorporated (e.g., Daugbjerg et al., 2000). This also applies to the blastodinian dinoflagellates. While Blastodinium has shown affinity to the Peridiniales in molecular phylogenic analyses (Skovgaard et al., 2007), other blastodinian species branch elsewhere within the Dinophyceae (Saldarriaga et al., 2004). According to molecular phylogenetics, Blastodiniphyceae, and Blastodiniales thus have no validity, a fact that may not be surprising when considering the peridinian morphology of the dinospores. However, a formal revision of the taxonomic position of Blastodinium has yet to be made and such revision may need to await a more general revision of the Peridiniales and related dinoflagellates.

Even though emerging SSU rDNA sequence data confirms a close taxonomic relation between individual Blastodinium species, 

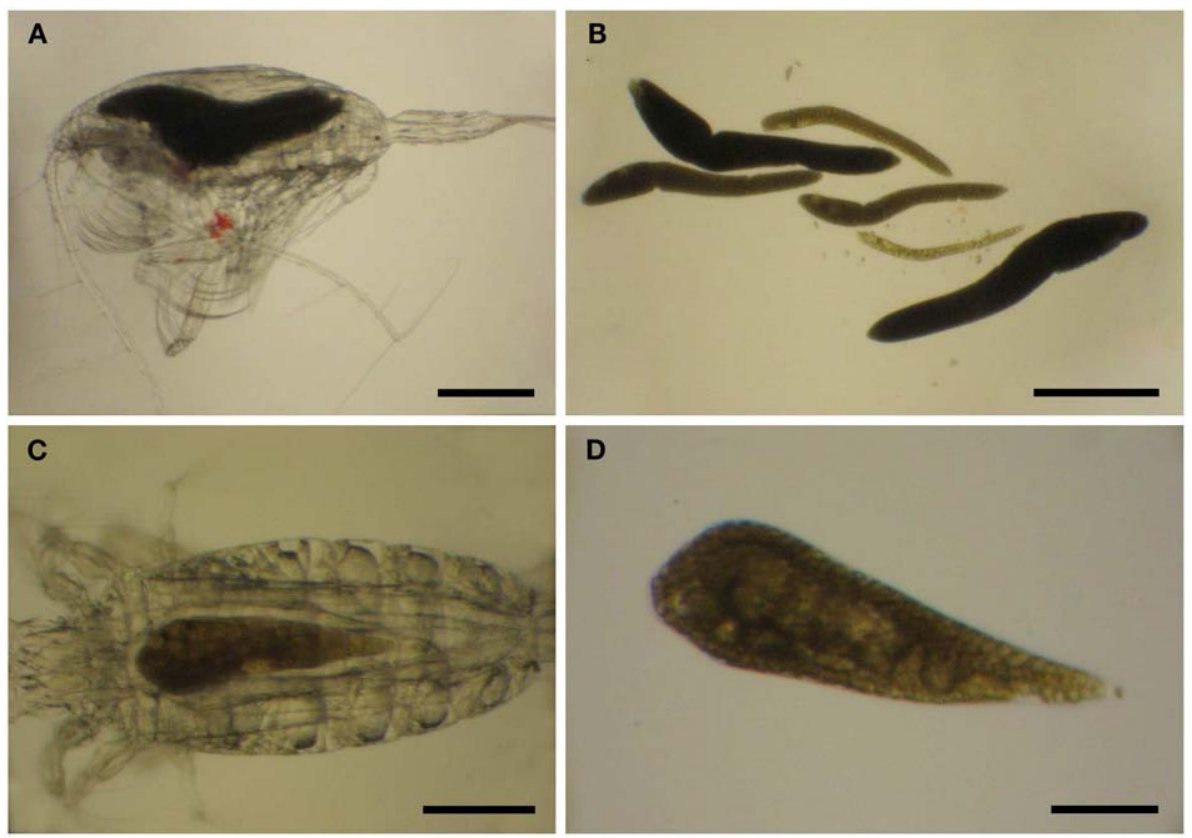

FIGURE 6 | Blastodinium sp. in Euchaeta sp. from the Atlantic Ocean. (A,C) Parasites inside their hosts. (B) Six parasites of an unidentifiable species from the host in (A). (C) A single unidentifiable parasite from the host in (C). (A,B) Scale bars $=500 \mu \mathrm{m}$. (C) Scale bar $=200 \mu \mathrm{m}$. (D) Scale bar $=100 \mu \mathrm{m}$.

these are not always monophyletic in phylogenetic analysis (Skovgaard et al., 2007; Alves-de-Souza et al., 2011). A couple of recent analyses have, on the other hand, shown Blastodinium to be monophyletic, but the support for this is consistently low (Coats et al., 2008; Skovgaard and Salomonsen, 2009). All these reports have, nevertheless, agreed that Blastodinium belong phylogenetically to the typical, dinophycean dinoflagellates.

\section{Intrageneric phylogeny}

Phylogenetic analyses (Maximum Likelihood, ML, and Bayesian inference, BI) of Blastodinium spp. based on 18S rDNA and ITS (ITS1, ITS2, and 5.8S rDNA) sequences are presented in Figure 7. Some of the more characteristic specimens sequenced for these analyses are depicted in Figures $\mathbf{8}$ and 9, including the two newly sequenced species $B$. inornatum and $B$. oviforme. These analyses do not address the potential of lack of monophyly among Blastodinium spp., since only Blastodinium sequences (including putative Blastodinium sequences) are included. Overall, the two data sets (18S rDNA vs. ITS) show consensus with moderate to high support for the contortum, spinulosum, and mangini groups (Figure 7), indicating that gross morphology does reflect molecular phylogeny within the genus. This is despite the fact that the two data sets are based in part on different samples. The mangini group has the poorest resolution among the three major groups, and has high support only in the ITS analyses (ML bootstrap value of 97 and BI posterior probability of 1.00). In the mangini group, only $B$. oviforme and $B$. navicula ITS sequences branch out as monophyletic. On the contrary, the positions of B. mangini (both trees) and B. galatheanum (ITS tree) do not agree exactly with the morphology-based classification, and in the $18 \mathrm{~S}$ phylogeny $B$. navicula is not well resolved. In particular B. mangini sequences are very diverse and this harmonizes with the high morphological variation described by Chatton (1920), leading him to erect B. mangini var. oncaea. The isolate BOUM7 (Blastodinium sp.) clusters together with the mangini group with a long branch. Indeed, in a previous analysis including also a number of nonBlastodinium dinoflagellates, the BOUM7 isolate branched out separately from the other Blastodinium clades (Alves-de-Souza et al., 2011).

The consistent high support for the contortum group suggests that these sequences may in fact comprise a single species (Figure 7), which is here represented from different host species and different locations (Mediterranean Sea and Gulf of California). The spinulosum group, on the contrary, is as a whole well supported, but it is very diverse and the individual clades do not conform entirely with the identification of species as determined through morphological traits. Most typical B. spinulosum morphotype sequences do branch in one clade (Group spinulosum I), but this clade also encompasses B. pruvoti, B. inornatum, and $B$. crassum morphotypes (Figure 7). On the other hand, B. spinulosum morphotype sequences are also present in the spinulosum II clade. One of these B. spinulosum morphotypes (BCL01) was morphologically distinct by comprising eight individuals of which two were apparently colorless (Figure 9G).

In conclusion, it is probable that both the mangini group and the spinulosum group(s) encompass one or more species complexes and that, possibly, a larger species diversity than currently recognized exists within Blastodinium. A high genetic diversity within B. mangini was to be expected considering the large number of hosts known for this species and the fact that the morphology of B. mangini can be quite variable (Chatton, 1920). Unfortunately, sequences from $B$. hyalinum, B. chattoni, and B. apsteini 


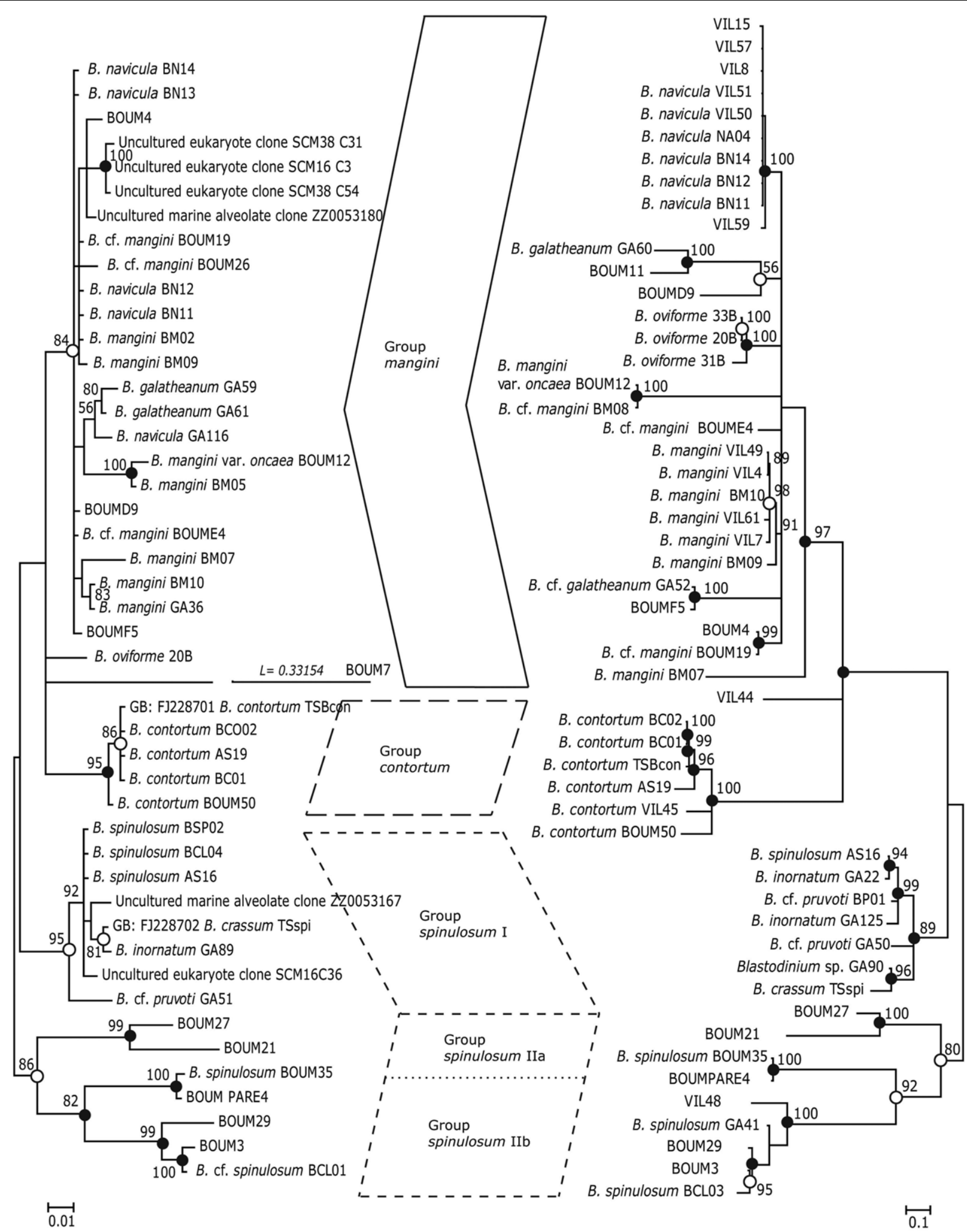

FIGURE 7 | Phylogenetic trees based on Bayesian analyses of alignments comprising SSU rDNA sequences (left) and ITS1, 5.8S rDNA, and ITS2 sequences (right) of Blastodinium spp. Numbers above nodes are Maximum Likelihood bootstrap values; only values above $50 \%$ are shown. Filled circles at nodes denote that the clade had Bayesian posterior probabilities (PP) of 1.00; open circles denote PP of 0.95-0.99. PP $<95$ are not shown. Labels at branches are species names and/or isolate names. Two sequences are identified by their GenBank accession number; these have the prefix "GB:" GenBank accession numbers for all sequences are given in Table A1 in Appendix. 

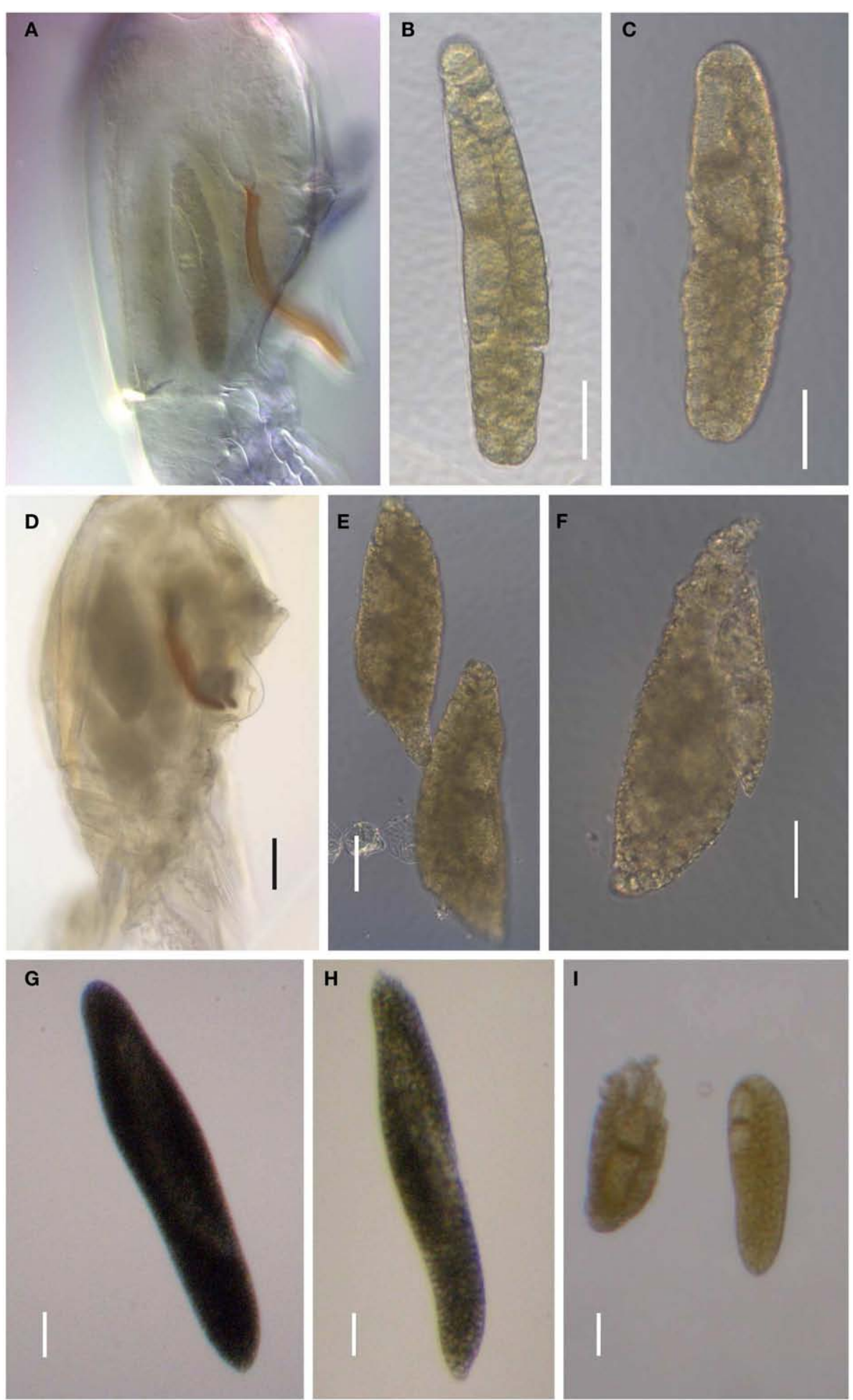

FIGURE 8 | Blastodinium spp. (A-C) Blastodinium mangini. (A) Three individuals inside Farranula rostrata (Villefranche-sur-mer, 2 of September 2009). Monoblastic stage (I-128). (B) Individual extracted from F. rostrata (Villefranche-sur-mer, 3 of September 2009, VIL49). Monoblastic stage (I-64). (C) Individual extracted from F. rostrata (Villefranche-sur-mer, 2 of September 2009, VIL52). Monoblastic stage (I-128). (D-F) B. navicula. (D) Four individuals inside F. rostrata (Villefranche-sur-mer, 2 of September
2009, VIL50). (E,F) Different individuals extracted from the precedent copepod host (VIL50). Monoblastic stage (I-128). (G) Blastodinium cf. galatheanum from Acartia negligens (North Atlantic, GA52). (H) $B$. galatheanum. from A. negligens (North Atlantic, GA60). Scale bar $=50 \mu \mathrm{m}$. I. B. mangini var. oncaea. Two individuals from Oncaea sp. (NW Mediterranean Sea, BM05). (B,C) Scale bars $=50 \mu \mathrm{m}$. (D) Scale bar $=100 \mu \mathrm{m}$. (E-I) Scale bars $=50 \mu \mathrm{m}$. (G) 

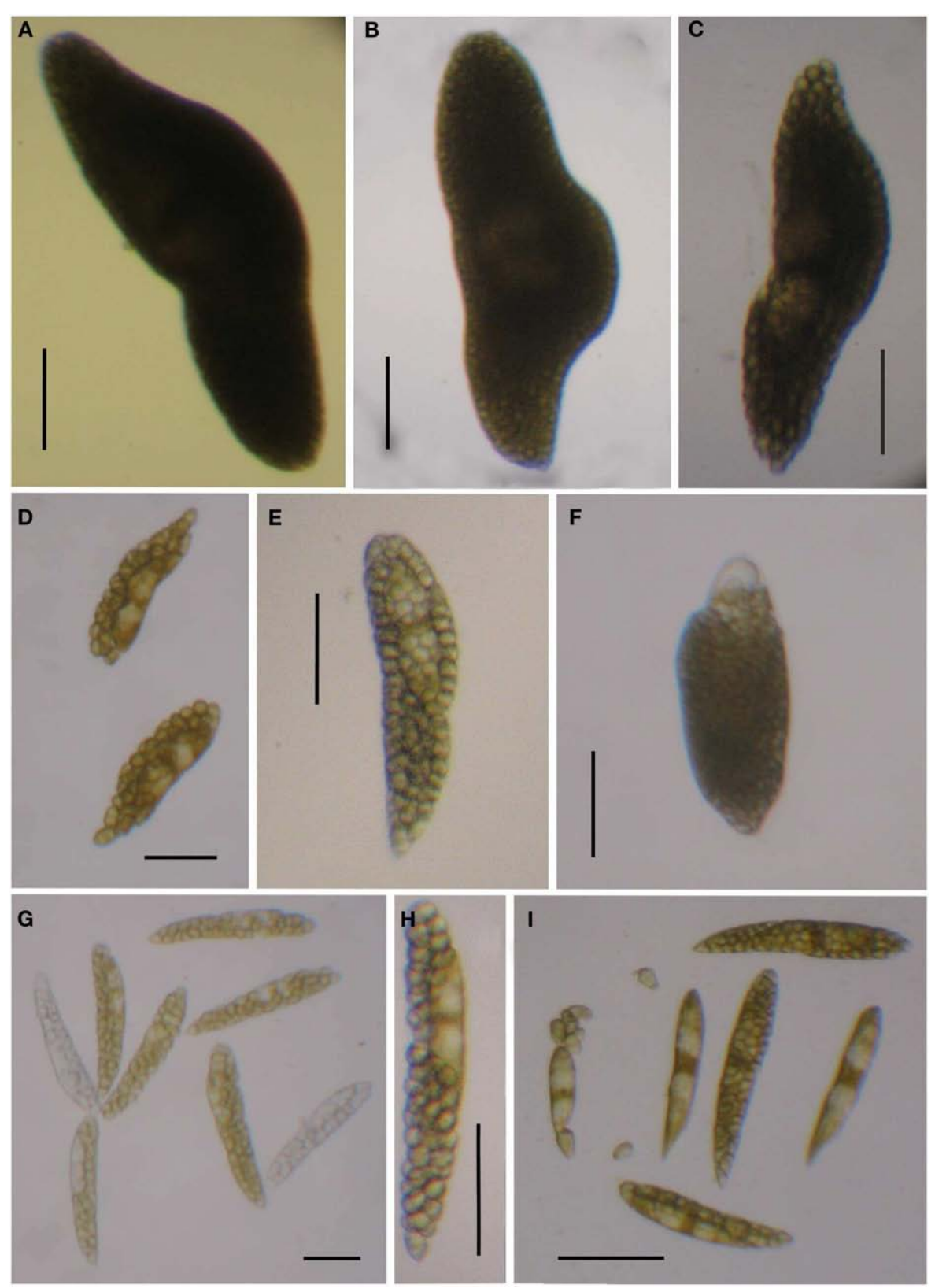

FIGURE 9 | Blastodinium spp. Sequences from samples are used for the phylogenetic analyses in Figure 7. (A-C) Solitary individual of B. inornatum Group spinulosum I from Clausocalanus spp. (A) GA22. (B) GA89. (C) GA125. (D-F) Gregarious individuals of Blastodinium spp. Group spinulosum I from Clausocalanus spp. (D) Blastodinium cf. pruvoti, BP01. (E) Blastodinium cf. pruvoti, GA50. (F) B. oviforme from Oithona similis. (G,H) Gregarious individuals of B. spinulosum Group spinulosum II. (G) Blastodinium cf. spinulosum, BCL01, from Clausocalanus cf. arcuicornis. Note two colorless individuals. (H) $B$. spinulosum, GA41, from Paracalanus parvus. (I) B. spinulosum, BCL04, Group spinulosum I from Clausocalanus sp. Scale bars $=100 \mu \mathrm{m}$. are currently not available and the phylogenetic position of these colorless species is, thereby, unknown.

\section{OCCURRENCE}

\section{Species distribution}

Reports on Blastodinium spp. suggest that the genus occurs worldwide in seawater with close to full strength salinity, i.e., more than approximately $30 \mathrm{ppt}$. (Figure 10). Most observations on
Blastodinium have been done in coastal waters, but this pattern is likely to reflect the ease of access to sampling sites rather than the actual distribution of the organisms. Based on the work by Apstein (1911) and subsequent observations, Chatton (1929) noted that B. hyalinum was the only species present in the cold temperate North Sea, whereas a row of green (photosynthetic) species existed in warm temperate waters of the Mediterranean Sea. This observation concurs with that of subsequent studies, 


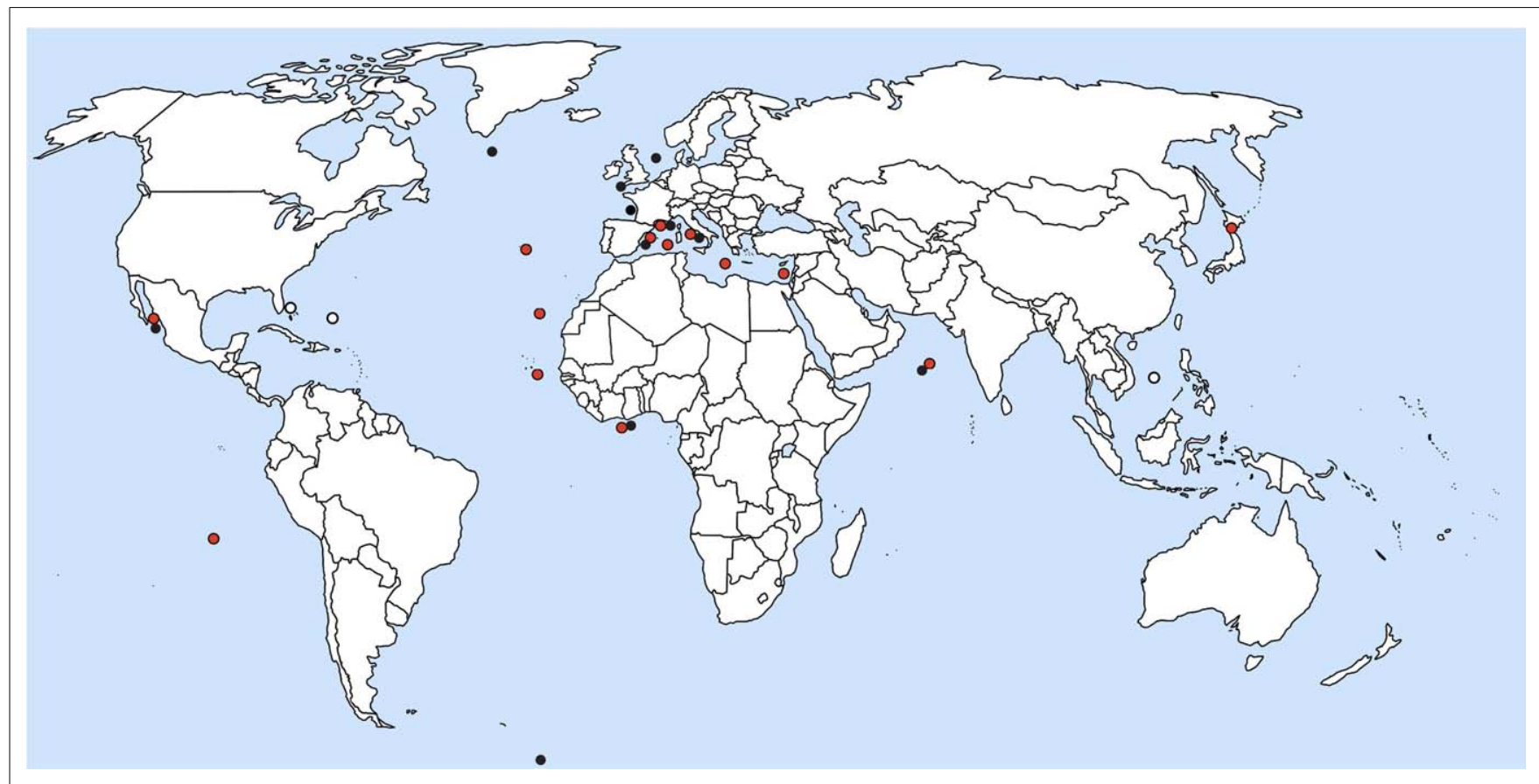

FIGURE 10 | Location of current reports of Blastodinium spp. in marine copepods. Red circles represent photosynthetic species; black circles are colorless species; and white circles are environmental DNA sequences with high similarity to Blastodinium.

finding exclusively B. hyalinum in cold temperate waters (Lebour, 1925; Jepps, 1937; Vane, 1952). Also the species reported by Øresland (1991) in Euchaeta antarctica from Antarctic waters was presumably $B$. hyalinum considering the length of the parasite (2.5-3.5 mm; Øresland, 1991), matching no other known Blastodinium species. As further support for B. hyalinum being a world-wide species, Figures 11A,B depict B. hyalinum in Calanus sp. from Greenlandic waters. On the other hand, photosynthetic species of Blastodinium are restricted to warm temperate, subtropical, and tropical waters. These waters are often oligotrophic suggesting that the life strategy of Blastodinium spp. has adapted to such an environment. One may speculate that a semi-parasitic organism, a "parasitic alga," as Blastodinium will benefit from being able to acquire inorganic nutrient from its host in oligotrophic waters, thereby avoiding potential nutrient limitation. Considering the relatively small number of surveys, it is to be expected that both the geographic range and the host range of Blastodinium are broader than now recognized. A further addition to the known geographic range of Blastodinium cf. chattoni is given in Figures 11C,D, showing this parasite in Cosmocalanus vulgaris collected in the Central Atlantic Ocean off the West coast of Africa by Skovgaard and Salomonsen (2009). From the same waters, a rare example of a Temora stylifera was also found infected with a Blastodinium (Figures 11E,F), in this case a species that was identified as an early developmental stage of B. contortum.

\section{Occurrence of dinospores}

Free-swimming Blastodinium cells (dinospores) are rarely encountered in the marine plankton. This may be because dinospores are short-lived and therefore less likely to be detected, but it is also possible that Blastodinium dinospores are overlooked due to their superficial resemblance with free-living, non-parasitic peridinoid dinoflagellates. Alves-de-Souza et al. (2011) found numerous dinospores in the Mediterranean Sea using DNAprobes and proposed that some of the "small thecate dinoflagellates" often observed in mixed plankton samples may in fact be Blastodinium dinospores. Also, SSU rDNA sequences from Sargasso Sea nanoplankton show high similarity with Blastodinium spp. and are most likely to originate from Blastodinium dinospores (Skovgaard and Salomonsen, 2009). The same may apply for two ITS1 sequences from the South China Sea (GenBank accession numbers GU941876 and GU942050). Little is known about the vertical distribution of Blastodinium spp. dinospores, but Alvesde-Souza et al. (2011) found maximum densities of dinospores at or just below the deep chlorophyll maximum in the Mediterranean Sea (approximately $100 \mathrm{~m}$ ), i.e., in an environment where photosynthetic growth is unlikely to be of any significance. Occurrence of Blastodinium spp. is seasonal (Chatton, 1920; Skovgaard and Saiz, 2006) suggesting that the life cycle may contain a dormant stage. Indeed, Chatton (1920) mentioned the presence of cysts, but their fate and function remain unknown.

\section{Host-specificity}

Most Blastodinium species infest several copepod host species. This was originally realized on the basis of Blastodinium morphology (Chatton, 1920; Sewell, 1951) and it is corroborated by recent ITS sequences. For example sequences of isolate VIL61 from Triconia sp. were identical to VIL4 and VIL49 (Figure 8B) from F. rostrata. However, there is a clear distinction between species that infect calanoid copepods and those that infect cyclopoid copepods. This pattern was noted already by Chatton (1920, p. 236) and has been corroborated in subsequent investigations (Table 1). Also, there 

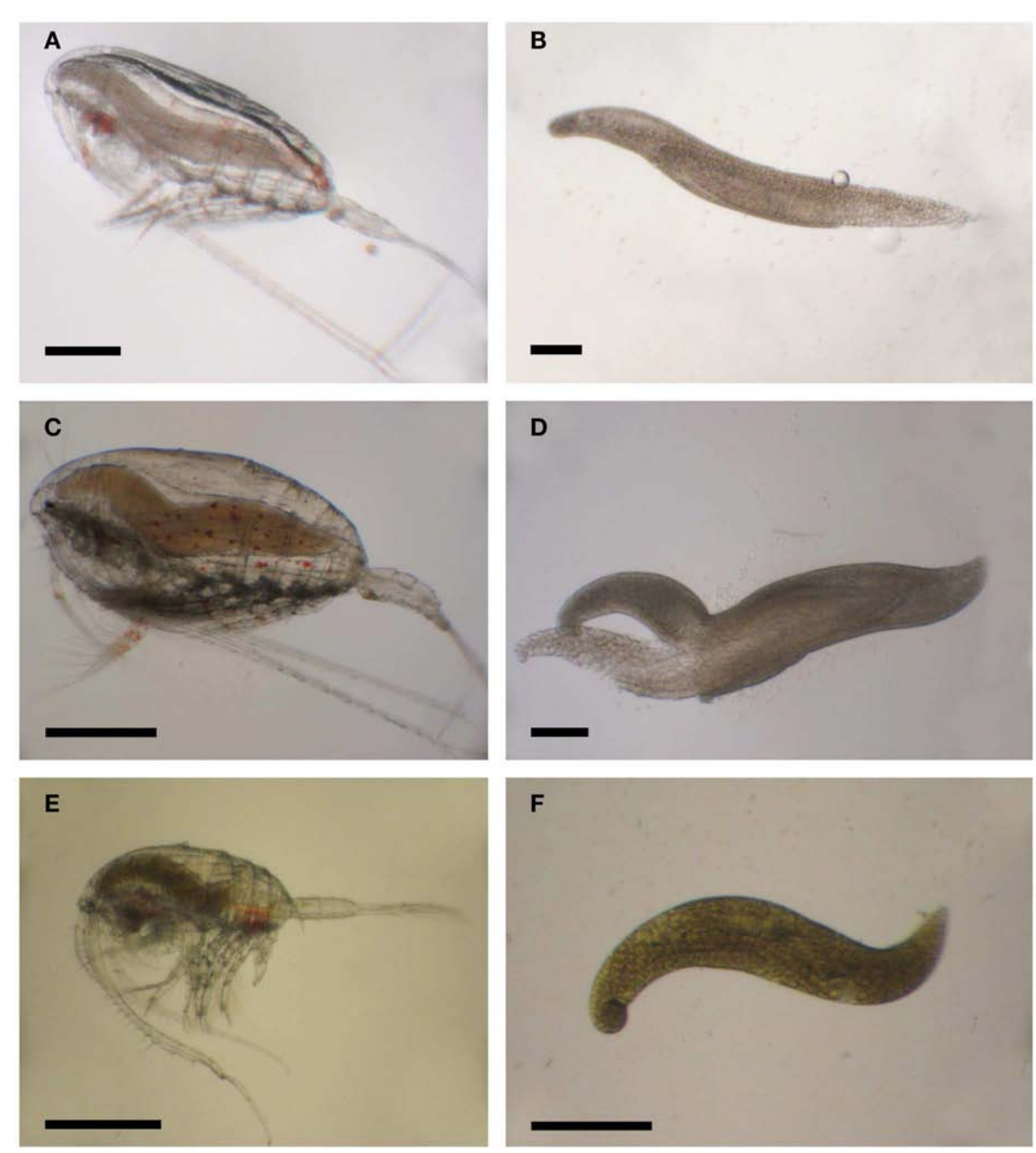

FIGURE 11 | Blastodinium spp. in calanoid copepods. (A) Calanus sp. from Greenlandic waters with B. hyalinum. (B) Parasite from (A). (C)

Cosmocalanus vulgaris off the West coast of Africa with Blastodinium cf. chattoni. (D) Parasite from (C). (E) Temora stylifera from the Central Atlantic Ocean with Blastodinium cf. contortum. (F) Parasite from (E). (A,C,E) Scale bars $=500 \mu \mathrm{m} ;(\mathbf{B}, \mathbf{D}, \mathbf{F})$ scale bars $=200 \mu \mathrm{m}$. is a large variation in the number of host species a single Blastodinium species is able to infect, even though this observation may depend on how commonly the parasite species is observed. It is interesting to note that several common copepod species, such as Oithona nana and T. stylifera, are rarely infected with Blastodinium spp. in mixed plankton communities in which several other copepod species have high infection prevalence (Skovgaard and Saiz, 2006).

\section{ECOLOGY}

\section{Photosynthetic growth}

The gut of planktonic copepods has been shown to be a suitable environment for photosynthesis (Epp and Lewis, 1981) and since most Blastodinium species possess well-developed chloroplasts it is natural to assume that they are capable of photosynthesis. Pasternak et al. (1984) demonstrated that this is in fact the case and made the crude estimate that Blastodinium sp. was able to fulfill approximately half of its energy needs through photosynthesis, implying that the other half must somehow be obtained from the host. To further test this, the photosynthetic rate of Blastodinium cf. mangini hosted by Oncaea spp. (Figure 12A) was determined in November in the NW Mediterranean Sea (Table 2). The photosynthetic rate, $\mathrm{P}$, was up to $826 \mathrm{pg} \mathrm{C}$ parasite $\mathrm{p}^{-1} \mathrm{~h}^{-1}$ corresponding to a $\mathrm{P}$ per volume of the parasite of $1.6 \mathrm{ng} \mathrm{C} \mathrm{cm}^{-3} \mathrm{~h}^{-1}$. At the lower irradiance of $50-150 \mu \mathrm{E} \mathrm{m}^{-2} \mathrm{~s}^{-1}, \mathrm{P} / \mathrm{vol}$ was $0.6-0.9 \mathrm{ng}$ $\mathrm{C} \mathrm{cm}^{-3} \mathrm{~h}^{-1}$. The magnitude of $\mathrm{P}$ may be put in perspective by comparing with $\mathrm{P}$ of mixotrophic free-living dinoflagellates with a known relative contribution of photosynthesis for cell growth: $\mathrm{P} /$ vol of Gyrodinium resplendens was $2.5 \mathrm{ng} \mathrm{C} \mathrm{cm}^{-3} \mathrm{~h}^{-1}$ at $75 \mu \mathrm{E}$ $\mathrm{m}^{-2} \mathrm{~s}^{-1}$ (Skovgaard, 2000), and P/vol of Fragilidium subglobosum was $2.8 \mathrm{ng} \mathrm{C} \mathrm{cm}^{-3} \mathrm{~h}^{-1}$ at $150 \mu \mathrm{E} \mathrm{m}^{-2} \mathrm{~s}^{-1}$ (Skovgaard et al., 2000). Hence, the photosynthetic activity of Blastodinium cf. mangini is less than half of that of the two free-living, mixotrophic dinoflagellates. F. subglobosum acquired only $10 \%$ of its C needs through photosynthesis under the conditions at which $\mathrm{P}$ was measured (Skovgaard et al., 2000), and G. resplendens acquired approximately $16 \%$ of its $\mathrm{C}$ demand through photosynthesis. Assuming that all factors are equal, Blastodinium cf. mangini should then 
Table 2 | Photosynthetic rates, P, of Blastodinium sp. inside Oncaea sp. at four different irradiances.

\begin{tabular}{|c|c|c|c|}
\hline $\begin{array}{l}\text { Irradiance } \\
\left(\mu \mathrm{mol} \text { photons } \mathrm{m}^{-2} \mathrm{~s}^{-1} \text { ) }\right.\end{array}$ & $\begin{array}{l}P^{a}(p g C \\
\left.\text { parasite }{ }^{-1} h^{-1}\right)\end{array}$ & $\begin{array}{l}\text { SE } \\
(n=3)\end{array}$ & $\begin{array}{l}\mathrm{P} / \mathrm{vol}^{\mathrm{b}} \\
\left(\mathrm{ngC} \mu \mathrm{m}^{-3} \mathrm{~h}^{-1}\right)\end{array}$ \\
\hline 50 & 400 & - & 0.6 \\
\hline 150 & 509 & 6 & 0.9 \\
\hline 250 & 574 & 26 & 1.1 \\
\hline 350 & 826 & 13 & 1.6 \\
\hline
\end{tabular}

${ }^{a}$ Each replicate contained two copepods hosting each two parasites, i.e., measured $P$ was four times that reported here.

${ }^{b} P$ per volume of parasite. Volume calculated according to a prolate ellipsoid. Average dimension of parasites used: $L=200 \mu \mathrm{m}, W=70 \mu \mathrm{m}$.

acquire an even smaller fraction of its $\mathrm{C}$ needs through photosynthesis. According to this crude approximation, the estimate that Blastodinium sp. should fulfill approximately half of its energy needs through photosynthesis (Pasternak et al., 1984) is not unrealistic, but may be a comparatively high estimate. The existence of Blastodinium species with apparently non-functional chloroplasts (i.e., the colorless species) gives good reason to believe that Blastodinium spp. are able to obtain a substantial part of their energy needs heterotrophically through organic substances acquired from the host.

Blastodinium dinospores also contains chloroplasts (Figure 5I), suggesting a potential for photosynthetic growth. This could hypothetically be an advantage for the dispersal of the parasite, since dinospores would be able to stay alive for longer time outside their host. However, in a culture experiment, $B$. mangini dinospores did not survive for longer than a week, regardless whether they were incubated in light or in the dark (Skovgaard, 2005). Yet, in the optimum environment one would still expect a beneficial effect of chloroplasts for the survival time of dinospores and this could potentially increase the probability of finding a new suitable host. It is also possible, on the other hand, that the main photosynthetic activity occurs in the sporocytes, thereby supporting growth of the parasite inside the host. According to this hypothesis, the chloroplasts in dinospores may be a vestige from the preceding photosynthetic stage.

\section{EFFECTS ON THE HOST \\ Growth and fitness}

Infection with Blastodinium spp. generally leads to a reduced size of the infected host (Chatton, 1920; Sewell, 1951; Alves-de-Souza et al., 2011). This may be caused by food limitation induced by the parasite physically blocking the alimentary tract, but it is also possible that the parasite is utilizing organic matter in the gut, thereby competing with the host for the ingested food. Infected copepods also have a decreased survival as compared to uninfected copepods, which is possibly caused by the same food limitation mechanisms (Skovgaard, 2005). One could speculate that hosting a photosynthetic organism would be advantageous for the host and that the parasite would a beneficial symbiont supplying its host with organic matter. However, a comparison of survival of infected vs. uninfected Oncaea spp. incubated both in light and in the dark did not reveal any difference and thus did not give any support for Blastodinium being beneficial to its host (Skovgaard, 2005).

\section{Castration}

Blastodinium spp. is able to induce castration of infected female copepods (Chatton, 1920; Sewell, 1951; Skovgaard, 2005) and gonads are usually not fully developed in infected organisms (Chatton, 1920). Incubation experiments have demonstrated that infected copepods usually do not deposit eggs (Ianora et al., 1990; Skovgaard, 2005) and, even though infected females have been found carrying eggs at a few occasions (Vane, 1952; Skovgaard, 2005), hatching of eggs produced by an infected female copepod has never been witnessed. On the other hand, histological and ultrastructural examinations of Blastodinium-infected copepods, have shown ovaries and reproductive diverticulae to be normal in size and shape and oogonal development appeared comparable to uninfected individuals (Ianora et al., 1990). It thus appears that an infection with Blastodinium spp. does not necessarily destruct the gonad anatomy, as is the case with the more detrimental parasite Syndinium turbo (Ianora et al., 1990). The infection does, however, lead to physiological castration, which is probably induced by the parasite "stealing" energy from its host and/or by the mechanical pressure exerted by the parasite on the reproductive organs. Some parasitic castrators are able to modify the scheme by which the host allocates energy, thereby shunting resources from reproduction to growth (Hall et al., 2007). This mechanism is not likely to be of importance for Blastodinium spp. given the fact that infected copepods are smaller than healthy specimens.

\section{Female vs. male infection}

In general, only adult females and juveniles are infected with Blastodinium spp. Chatton (1920) found a large number of female and male copepodites to be infected, but did not find a single infected, adult male. He ascribed this to a failure of infected male copepodites of molting to the adult stage. Later studies have shown Oncaea spp. to be an exception to be above rule, since male Oncaea spp. are frequently infected with B. mangini (Sewell, 1951; Skovgaard, 2005) and so are males of species within Corycaeidae (Alves-de-Souza et al., 2011). Infections in adult males of other species are extremely rare: Sewell (1951) found a single adult Nanocalanus minor male to be infected with B. contortum. This represents the only of two examples of Blastodinium infection in an adult calanoid male, the other example being a male Acartia clausi observed by Ianora et al. (1990).

The prevailing hypothesis predicts that Blastodinium spp. are transmitted through oral infection. Such entry of infection would explain the lack of infection in adult males, since males of many copepod species are short-lived and do not have the capability to feed, in particular among the Clausocalanoidea (Ohtsuka and Huys, 2001). If infected, juvenile males are unable to molt to the adult stage; this would efficiently prevent the existence of infected males. Oncaea spp. are, on the other hand, among those species in which males do feed (Ohtsuka et al., 1996). Hence, the pattern of infection in males supports the hypothesis of oral transmission of infection. There are no records of behavioral changes in copepods due to infection with Blastodinium 
spp. On the contrary, males do mate with infected females (Cattley, 1948) and, in the case of Oncaea spp., both infected males and females have been observed mating, and even two infected individuals will mate with each other (Skovgaard, 2005; Figure 12B).

\section{Sex alternation}

Copepods parasitized by Blastodinium spp. have been observed to be morphologically intersexual (Jepps, 1937; Cattley, 1948; Sewell, 1951; Ianora et al., 1987) and this has been interpreted as parasiteinduced sex reversal (Cattley, 1948). However, the proof that parasitism is a main causal factor for intersexuality and sex reversal in copepods is non-existent, since sex alternation is common among copepods - also among non-parasitized individuals (Shields, 1994). Furthermore, intersex is caused by several factors other than parasitism, e.g., mortality, differential longevity, and environmental factors such food as limitation (Gusmão and McKinnon, 2009). Nevertheless, it does appear that intersexuality is more common among copepods parasitized by Blastodinium spp. than among non-parasitized copepods (Sewell, 1951 and parasitism should, therefore, be considered among the environmental factors causing intersexes in copepods (Gusmão and McKinnon, 2009).
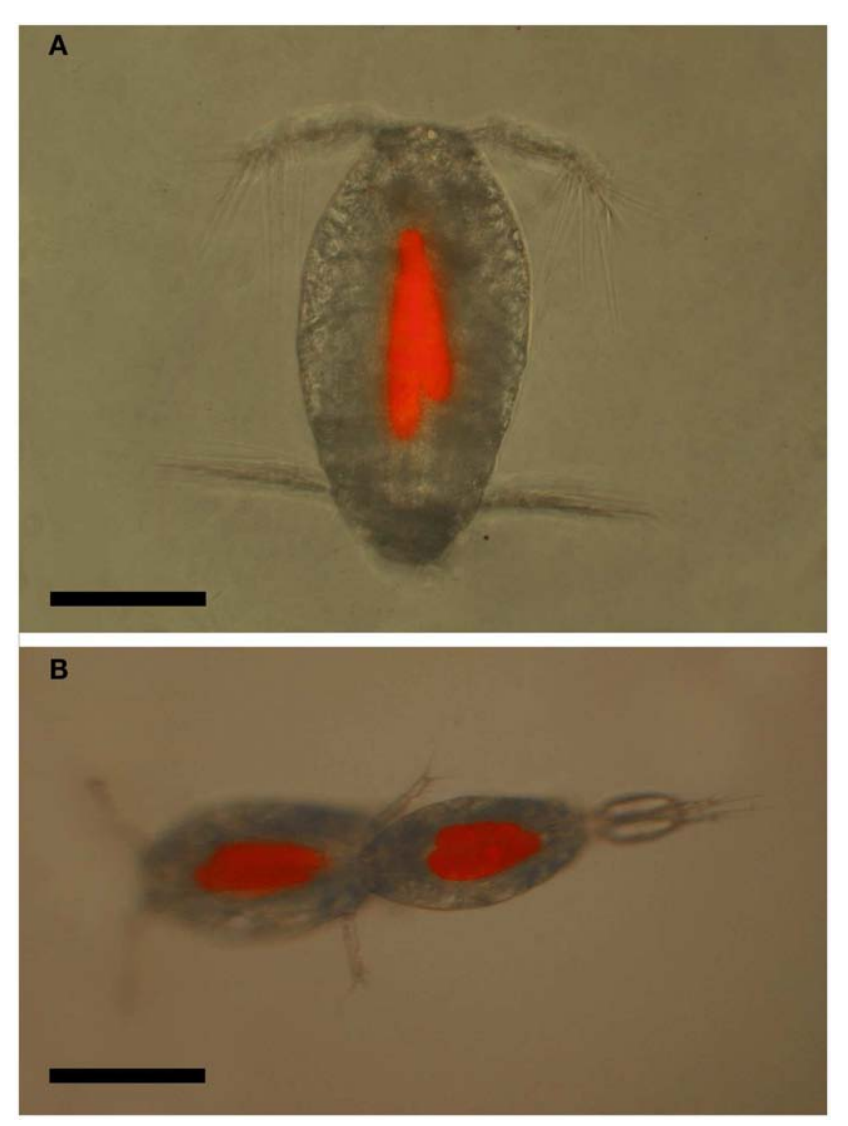

FIGURE 12 | Oncaea cf. scottodicarloi with Blastodinium mangini in epifluorescent illumination showing autofluorescence of parasite chloroplasts. (A) Female with two parasites. (B) Copulation male (right) and female (left), both infected with 2-3 parasites. Scale bars $=100 \mu \mathrm{m}$.

\section{Prevalence}

Most current knowledge on the occurrence, diversity, and prevalence of Blastodinium spp. is from the Mediterranean Sea and this is also the only site from where seasonal data are available. These data show marked seasonal variations and demonstrate that prevalence and diversity of the genus are highest from mid-summer through autumn; Blastodinium spp. are rare in late winter and during spring (Chatton, 1920; Skovgaard and Saiz, 2006). Quantitative investigations on Blastodinium spp. from the Mediterranean Sea and the Arabian Sea indicate that it is not unusual to find peaks among adult females of some copepod species with $20 \%$ or more infected (Table 3), but a prevalence below $5-10 \%$ is more common (Chatton, 1920; Sewell, 1951; Skovgaard and Saiz, 2006) and some copepod species are infected only to a very low extent. Limited quantitative data is available from cold temperate waters. Vane (1952) found overall infection rates of 3.7 and 3.8\% for adult and stage V females of Calanus finmarchicus and Pseudocalanus elongatus, respectively, from the Continuous Plankton Recorder samples taken from the North Sea (Hardy, 1941). Maximum infection rates were noted to be as high as 66 and $60 \%$, respectively, but sample sizes were, unfortunately, not specified. Other studies have found low numbers of parasites in the North Sea and adjacent waters (Apstein, 1911; Jepps, 1937).

Given the diversity and host-specificity of Blastodinium spp., a considerable effort is needed to assess the existence of all Blastodinium species in their respective potential hosts, and as a consequence, prevalence is often known only from sporadic investigations and often mainly for copepod species that tend to have highest degree of infection. This could imply that the general prevalence is overestimated. However, the opposite is more likely to be the case, because early developmental stages of parasites are almost certainly systematically overlooked and, furthermore, parasites are typically looked for in preserved samples in which the parasite have lost its color and become less conspicuous. The detection of endoparasites can be facilitated by fixation and storage of samples under conditions that preserve the color of the parasite (Skovgaard and Saiz, 2006), but even under optimum conditions early parasite stages are in risk of being overlooked. A solution to this problem may be to apply cell or DNA stains. Unspecific DNA dyes allow for a rapid detection of the DNA-rich nuclei of Blastodinium cells. A recent study used DNA-staining to detect infections and found relatively high infection prevalences; 51 and $33 \%$ for Corycaeidae and Calanoidae, respectively (Alves-de-Souza et al., 2011). It may also be possible to stain Blastodinium spp. differentially by use other standard staining techniques, such as hematoxylin. The practical feasibility of such staining techniques for quantitative samples is, however, in need for future validation.

\section{Effect on host populations}

Little is known about the impact of Blastodinium parasitism on natural copepod populations. The direct adverse effect of Blastodinium on fitness and survival of the infected host has been documented (Skovgaard, 2005), but has not been accounted for in field investigations. A single study has explored the adverse effect of Blastodinium spp. on the population of two copepod species. In this case it was estimated that impairment of the reproductive rate of Oncaea cf. scottodicarloi females infected with B. mangini 
Table 3 | Prevalence of Blastodinium spp. in different copepod hosts.

\begin{tabular}{llll}
\hline Parasite & Host & Prevalence(\%) & Location \\
\hline Blastodinium crassum & Paracalanus parvus & 1.5 & W Mediterranean Sea \\
B. contortum & Subeucalanus subtenuis* & $6-12$ & SE Pacific Ocean \\
& P. parvus & $0-3.9$ & W Mediterranean Sea \\
B. hyalinum & Calanus finmarchicus & $3.7-66$ & North Sea \\
& Pseudocalanus elongatus & $3.8-60$ & North Sea \\
& P. elongatus & $0.3-20.5$ & North Sea \\
& Paraeuchaeta antarctica ${ }^{+}$ & 6.6 & Weddel Sea \\
B. mangini & Oncaea cf. scottodicarloi & $0-17$ & W Mediterranean Sea \\
& Farranula rostrata & 10 & W Mediterranean Sea \\
B. navicula & Corycaeus giesbrechti & $20-30$ & W Mediterranean Sea \\
B. oviforme & Oithona spp. & $0-3$ & W Mediterranean Sea \\
B. spinulosum & P. parvus & $0.4-0.7$ & W Mediterranean Sea \\
Blastodium spp. & Clausocalanus spp. & 0.9 & W Mediterranean Sea \\
& P. parvus & 0.4 & W Mediterranean Sea \\
& Calanoida & $33^{\#}$ & E Mediterranean Sea \\
& Corycaeidae & $51^{\#}$ & E Mediterranean Sea \\
& Oithonidae & $<2^{\#}$ & E Mediterranean Sea \\
& Oncaeidae & $<2^{\#}$ & E Mediterranean Sea
\end{tabular}

*, The parasite was presumably B. contortum; ${ }^{+}$, the parasite was presumable B. hyalinum; ${ }^{*}$, based on DNA-stain screening.

1. Chatton (1920); 2, Pasternak et al. (1984); 3, Vane (1952); 4, Cattley (1948); 5, Oresland (1991); 6, Skovgaard and Saiz (2006); 7, lanora et al. (1987); 8, Alves-de-Souza et al. (2011).

was $0.05-0.16$ day $^{-1}$ and for P. parvus females infected with B. contortum the impairment was up to 0.03 day $^{-1}$ (Skovgaard and Saiz, 2006). The magnitude of reproductive impairment was concluded to be comparable in effect on host populations to that of sources of predator-induced mortality. Oncaea spp. males are also infected to a considerable extent (Sewell, 1951; Skovgaard, 2005, Figure 10B) and infected male and female copepods appear to copulate actively (Figure 12B), but possibly copulating with an infected male is never successful, thereby reducing a healthy female's probability of reproducing successfully with a fertile male. Thus, in addition to the parasite-induced castration of females, copulations in which any of the mates are infected will reduce the overall mating success rate, and infection of males will lead to an enforced reduction in this mating success. This mechanism may have a considerable effect on the recruitment success in individual copepod populations.

\section{CONCLUDING REMARKS}

Based on the above compilation of historical and recent data combined with new data presented here, it can be concluded that the genus Blastodinium is both morphologically and genetically very diverse. It is, thus, certain that the current number of described species does not reflect the actual diversity of the genus: several Blastodinium morphotypes and gene sequences cannot be assigned to any known species. Furthermore, DNA sequences from some of these aberrant morphotypes are highly divergent (such as the BOUM7 isolate; Alves-de-Souza et al., 2011). Therefore, the genus Blastodinium is not always monophyletic in phylogenetic analyses encompassing the entire Dinokaryota (Alves-de-Souza et al., 2011) and in those analyses that show a monophyletic origin of the genus, the support is typically negligible (Coats et al., 2008; Skovgaard and Salomonsen, 2009). Finally, as shown in the present study (Figures 7-9) there is only partial agreement between the morphological distinction of Blastodinium species and their separation in molecular phylogenetic analyses. This suggests that cryptic speciation exists within the genus and that morphological characters may be insufficient for the separation of individual species.

Even though most Blastodinium species contain functional plastids, there is no evidence of any beneficial effects for a copepod hosting a Blastodinium. As shown here, chloroplasts are not fully developed in the trophocyte and, thereby, seem to primarily play a role in the growth of sporocytes. However, as discussed above, Blastodinium individuals are conceivably highly dependent on organic matter acquired from the host and this energy flow may be a major cause of the harmful effects recorded on infected copepods. The effects of a Blastodinium infection is not detrimental to individual copepod hosts, but infection does lead to decreased fitness and physiological castration, which have the potential to significantly influence the affected copepod populations.

An accumulating number of investigations of the occurrence of Blastodinium spp. in the World's oceans strengthen earlier presumptions that photosynthetic species are common but restricted to warm oligotrophic oceans. On the other hand, the colorless species, at least B. hyalinum, appear to occur world-wide. Yet, most zooplankton studies do not report on the presence of Blastodinium because parasites are generally not considered in standard zooplankton counts and they are easily overlooked by the untrained eye. Nevertheless, the prevalence and effects of Blastodinium infections justify that these organisms should ideally be taken into account when assessing zooplankton productivity processes and an important task in future research will be to develop techniques that facilitate registration of parasites in routine zooplankton investigations. 


\section{ACKNOWLEDGMENTS}

This work was partly supported by the Danish National Strategic Research Council - IMPAQ - grant no. 10-093522 (Alf Skovgaard). Part of this study was carried out in connection with the Galathea 3 expedition under the auspices of the Danish Expedition Foundation. This is Galathea3 contribution No. P94. Sergey A. Karpov thanks CNRS for the invited professor grant (2009-2010),

\section{REFERENCES}

Alves-de-Souza, C., Cornet, C., Nowaczyk, A., Gasparini, S., Skovgaard, A., and Guillou, L. (2011). Blastodinium spp. infect copepods in the ultra-oligotrophic marine waters of the Mediterranean Sea. Biogeosciences 8, 2125-2136.

Apstein, B. (1911). Parasiten von Calanus finmarchicus. Wiss. Meeresunters. Abt. Kiel 19, 206-223.

Cattley, J. G. (1948). Sex reversal in copepods. Nature 161, 937-937.

Cavalier-Smith, T. (1993). Kingdom Protozoa and its 18 phyla. Microbiol. Rev. 57, 953-994.

Chatton, É. (1906). Les Blastodinides, ordre nouveuax de Dinoflagellés parasites. C. R. Acad. Sci. 144, 981-983.

Chatton, É. (1908). Note préliminare sur trois formes nouvelles de genre Blastodinium Chatton. Bull. Soc. Zool. Fr. 33, 134-137.

Chatton, É. (1911). Sur divers parasites de Copépodes pélagiques observés par M. Apstein. C. R. Acad. Sci. 153, 474-476.

Chatton, É. (1912). Diagnoses préliminare de Péridiniens parasites nouveaux. Bull. Soc. Zool. Fr. 37, 85-93.

Chatton, É. (1920). Les Péridiniens parasites: morphologie, reproduction, ethologie. Arch. Zool. Exp. Gen. 59, 1-475.

Chatton, É. (1929). Différenciation et isolement géographique d'une espèce (Blastodinium hyalinum $\mathrm{Ch}$.) par substitution partielle des conditions oecologiques (parasitisme hétérotrophe) aux conditions cosmiques (autotrophisme) de son existence. Arch. Zool. Exp. Gen. 68, $1-7$.

Coats, D. W. (1999). Parasitic life styles of marine dinoflagellates. $J$. Eukaryot. Microbiol. 46, 402-409.

Coats, D. W., Bachvaroff, T., Handy, S. M., Kim, S. Y., Gárate-Lizárraga, I., and Delwiche, C. F. (2008). Prevalence and phylogeny of parasitic dinoflagellates (genus Blastodinium) infecting copepods in the Gulf of California. CICIMAR Oceánides 23, 67-77.

Daugbjerg, N., Hansen, G., Larsen, J., and Moestrup, O. (2000). Phylogeny of some of the major genera of dinoflagellates based on ultrastructure and partial LSU rDNA sequence data, including the erection of three new genera of unarmoured dinoflagellates. Phycologia 39, 302-317.

Drebes, G. (1984). Life cycle and host specificity of marine parasitic dinophytes. Helgoländer Meeresunters 37, 603-622.

Drits, A., and Semenova, T. (1985). Some aspects of interrelations between marine copepods with algae of the genus Blastodinium (Peridiniales). Zool. Zhurnal. 64, 453-455.

Epp, R. W., and Lewis, W. M. (1981). Photosynthesis in Copepods. Science 214, 1349-1350.

Fensome, R. A., Saldarriaga, J. F., and Taylor, F. J. R. (1999). Dinoflagellate phylogeny revisited: reconciling morphological and molecular based phylogenies. Grana 38, 66-80.

Fensome, R. A., Taylor, F. J. R., Norris, G., Sarjeant, W. a. S., Wharton, D. I., and Williams, G. L. (1993). A Classification of Living and Fossil Dinoflagellates. Hanover, PA: Sheridan Press.

Fritz, L., and Triemer, R. E. (1985). A rapid simple technique utilizing Calcofluor White M2r for the visualization of dinoflagellate thecal plates. $J$. Phycol. 21, 662-664.

Gaines, G., and Elbrächter, M. (1987). "Heterotrophic nutrition," in Biology of Dinoflagellates, ed. F. J. R. Taylor (Oxford: Blackwell Scientific), 224-268.

Gottschling, M., and Plötner, J. (2004). Secondary structure models of the nuclear internal transcribed spacer regions and 5.8S rRNA in Calciodinelloideae (Peridiniaceae) and other dinoflagellates. Nucleic Acids Res. 32, 307-315.

Gusmão, L. F. M., and McKinnon, A. D. (2009). Sex ratios, intersexuality and sex change in copepods. J. Plankton Res. 31, 1101-1117.

Hall, S. R., Becker, C., and Cáceres, C. E. (2007). Parasitic castration: a perspective from a model of dynamic energy budgets. Integr. Comp. Biol. 47, 295-309.

and the RAS Presidium program "Problems of life origin and biosphere development" for partial support. We thank John Dolan for hosting us during sampling at Villefranche-sur-mer, Stéphane Gasparini for help with copepod species identification, and Cindy Cornet for her help in collecting samples. We thank Tsevetan Bachvaroff for providing us with the two ITS sequences from the Gulf of California.

Hardy, A. C. (1941). Continuous Plankton records: introduction to the North Sea survey, 1938-1939. Hull. Bull. Mar. Ecol. 2, 1-17.

Huelsenbeck, J. P., and Ronquist, F. (2001). MRBAYES: Bayesian inference of phylogenetic trees. Bioinformatics 17, 754-755.

Ianora, A., Mazzocchi, M., and Scotto di Carlo, B. (1987). Impact of parasitism and intersexuality on Mediterranean populations of Paracalanus parvus (Copepoda: Calanoida). Dis. Aquat. Org. 3, 29-36.

Ianora, A., Scotto di Carlo, B., Mazzocchi, M., and Mascellaro, P. (1990). Histomorphological changes in the reproductive condition of parasitized marine planktonic copepods. J. Plankton Res. 12, 249-258.

Jepps, M. W. (1937). On the protozoan parasites of Calanus finmarchicus in the Clyde Sea area. Q. J. Microsc. Sci. 79, 589-658.

Lebour, M. V. (1925). The Dinoflagellates of Northern Seas. Plymouth: The Marine Biological Association of the United Kingdom.

Nylander, J. A. A. (2004). MrModeltest v2. Program Distributed by the Author. Uppsala: Evolutionary Biology Centre, Uppsala University.

Ohtsuka, S., Böttger-Schnack, R., Okada, M., and Onbé, T. (1996). In situ feeding habits of Oncaea (Copepoda: Poecilostomatoida) from the upper $250 \mathrm{~m}$ of the central Red Sea, with special reference to consumption of appendicularian houses. Bull. Plankton Soc. Jpn. 48, 89-105.

Ohtsuka, S., and Huys, R. (2001). Sexual dimorphism in calanoid copepods: morphology and function. Hydrobiologia 453, 441-466.

Øresland, V. (1991). Feeding of the carnivorous copepod Euchaeta antarctica in Antarctic waters. Mar. Ecol. Prog. Ser. 78, 41-47.

Parsons, T. R., Maita, Y., and Lalli, C. M. (1984). A Manual of Chemical and Biological Methods for Seawater Analysis. Oxford: Pergamon Press.

Pasternak, A. F., Arashkevich, G., and Sorokin, Y. S. (1984). The role of the parasitic algal genus Blastodinium in the ecology of planktic copepods. Oceanology 24, 748-751.

Razouls, C., Bovée, D. F., Kouwenberg, J., and Desreumaux, N. (2005-2012). Diversity and Geographic Distribution of Marine Planktonic Copepods. Available at: http://copepodes.obsbanyuls.fr/en [accessed January 05, 2012].

Saldarriaga, J. F., Taylor, F. J. R., CavalierSmith, T., Menden-Deuer, S., and Keeling, P. J. (2004). Molecular data and the evolutionary history of dinoflagellates. Eur. J. Protistol. 40, 85-111.

Saunders, G. W., Hill, D. R. A., Sexton, J. P., and Andersen, R. A. (1997). Small-subunit ribosomal RNA sequences from selected dinoflagellates: testing classical evolutionary hypotheses with molecular systematic methods. Plant Syst. Evol. Suppl. 11, 237-259.

Sewell, R. B. (1951). The epibionts and parasites of the planktonic Copepoda of the Arabian Sea. John Murray expedition. Sci. Rep. Br. Mus. Nat. Hist. 9, 255-394.

Shields, J. D. (1994). The parasitic dinoflagellates of marine crustaceans. Annu. Rev. Fish. Dis. 4, 241-271.

Skovgaard, A. (2000). A phagotrophically derivable growth factor in the plastidic dinoflagellate Gyrodinium resplendens (Dinophyceae). J. Phycol. 36, 1069-1078.

Skovgaard, A. (2005). Infection with the dinoflagellate parasite Blastodinium spp. in two Mediterranean copepods. Aquat. Microb. Ecol. 38, 93-101.

Skovgaard, A., Hansen, P. J., and Stoecker, D. K. (2000). Physiology of the mixotrophic dinoflagellate Fragilidium subglobosum. I. Effects of phagotrophy and irradiance on photosynthesis and carbon content. Mar. Ecol. Prog. Ser. 201, 129-136.

Skovgaard, A., Massana, R., and Saiz, E. (2007). Parasitic species of the genus Blastodinium (Blastodiniphyceae) are peridinioid dinoflagellates. J. Phycol. 43, 553-560. 
Skovgaard, A., and Saiz, E. (2006). Seasonal occurrence and role of protistan parasites in coastal marine zooplankton. Mar. Ecol. Prog. Ser. 327, 37-49.

Skovgaard, A., and Salomonsen, X. M. (2009). Blastodinium galatheanum sp. nov. (Dinophyceae) a parasite of the planktonic copepod Acartia negligens (Crustacea, Calanoida) in the central Atlantic Ocean. Eur. J Phycol 44, 425-438.

Soyer, M. O. (1970). Etude ultrastructurale de l'endoplasme et des vacuoles chez deux types de Dinoflagellés aux genres Noctiluca (Suriray) et Blastodinium (Chatton). Z. Zellforsch. Mikrosk. Anat. 105, 350-388.

Soyer, M. O. (1971). Structure du noyau des Blastodinium (Dinoflagellés parasites). Chromosoma 33, 70-114.

Soyer-Gobillard, M. O. (2006). Edouard Chatton (1883-1947) and the dinoflagellate protists: concepts and models. Int. Microbiol. 9, 173-177.

Vane, F. R. (1952). The distribution of Blastodinium hyalinum in the North Sea. Challenger Soc 3, 23-24.
Conflict of Interest Statement: The authors declare that the research was conducted in the absence of any commercial or financial relationships that could be construed as a potential conflict of interest.

Received: 15 May 2012; accepted: 31 July 2012; published online: 28 August 2012.

Citation: Skovgaard A, Karpov SA and Guillou L (2012) The parasitic dinoflagellates Blastodinium spp. inhabiting the gut of marine, planktonic copepods: morphology, ecology, and unrecognized species diversity. Front. Microbio. 3:305. doi: 10.3389/fmicb.2012.00305

This article was submitted to Frontiers in Aquatic Microbiology, a specialty of Frontiers in Microbiology.

Copyright (C) 2012 Skovgaard, Karpov and Guillou. This is an open-access article distributed under the terms of the Creative Commons Attribution License, which permits use, distribution and reproduction in other forums, provided the original authors and source are credited and subject to any copyright notices concerning any third-party graphics etc. 


\section{APPENDIX}

Table A1 | GenBank accession numbers for the sequences used in Figure 7.

\begin{tabular}{|c|c|c|c|c|c|c|}
\hline Species & Isolate & Host & $\begin{array}{l}\text { Number of Blastodinium } \\
\text { ind. per host }\end{array}$ & Sampling site & ssu & ITS \\
\hline \multicolumn{7}{|l|}{ B. contortum } \\
\hline B. contortum & BC01 & Clausocalanus arcuicornis & 1 & NW Med. Sea & DQ317537 & $J \times 473669$ \\
\hline B. contortum & TSBcon & Paracalanus parvus cf. & 1 & Gulf of California & FJ228701 & FJ228701 \\
\hline B. contortum & VIL45 & Paracalanus parvus & 1 & Med. Sea & - & JX473688 \\
\hline \multicolumn{7}{|l|}{ B. crassum } \\
\hline B. crassum & TSspi & Paracalanus parvus cf. & 1 & Gulf of California & FJ228702 & FJ228702 \\
\hline \multicolumn{7}{|l|}{ B. galatheanum } \\
\hline B. galatheanum & GA59 & Acartia negligens & 1 & Atlantic Ocean & FJ541187 & - \\
\hline B. inornatum & GA89 & Clausocalanus sp. & 1 & Atlantic Ocean & HO226069 & - \\
\hline B. inornatum & GA22 & Clausocalanus sp. & 1 & Atlantic Ocean & - & JX473672 \\
\hline B. inornatum & GA125 & Calanoida & 1 & Atlantic Ocean & - & JX473673 \\
\hline \multicolumn{7}{|l|}{ B. mangini } \\
\hline B. mangini & BM02 & Oncaea sp. & 3 & NW Med. Sea & JX473655 & - \\
\hline B. mangini & BM05 & Oncaea sp. & 2 & NW Med. Sea & JX473656 & - \\
\hline B. mangini & BM07 & Oncaea sp. & 2 & NW Med. Sea & $J X 473657$ & JX473674 \\
\hline B. cf. mangini & BM08 & Oncaea sp. & 2 & NW Med. Sea & - & JX473675 \\
\hline B. mangini & BM09 & Oncaea sp. & nd & NW Med. Sea & JX473664 & JX473664 \\
\hline B. mangini & BM10 & Oncaea sp. & nd & NW Med. Sea & JX473658 & JX473676 \\
\hline B. mangini & GA36 & Oncaea sp. & 3 & Atlantic Ocean & JX473659 & - \\
\hline \multicolumn{7}{|l|}{ B. navicula } \\
\hline B. navicula & BN11 & Corycaeus giesbrechti & nd & NW Med. Sea & DQ317538 & JX473677 \\
\hline B. navicula & BN12 & C. giesbrechti & nd & NW Med. Sea & JX473665 & JX473665 \\
\hline B. navicula & $\mathrm{BN} 13$ & C. giesbrechti & nd & NW Med. Sea & JX473660 & - \\
\hline B. navicula & BN14 & C. giesbrechti & nd & NW Med. Sea & JX473661 & JX473678 \\
\hline B. navicula & GA116 & Corycaeus furcifer & 8 & Atlantic Ocean & JX473662 & - \\
\hline B. navicula & NA04 & C. giesbrechti & 4 & NW Med. Sea & - & JX473679 \\
\hline B. navicula & VIL50 & Corycaeus sp. & 4 & Med. Sea & - & JX473693 \\
\hline B. navicula & VIL51 & Corycaeus sp. & 7 & Med. Sea & - & JX473694 \\
\hline Blastodinium sp. & VIL15 & Corycaeus sp. & 1 & Med. Sea & - & JX473695 \\
\hline Blastodinium sp. & VIL57 & Farranula rostrata & 5 & Med. Sea & - & JX473696 \\
\hline Blastodinium sp. & VIL8 & C. cf. giesbrechti & 5 & Med. Sea & - & JX473697 \\
\hline Blastodinium sp. & VIL59 & Farranula rostrata & 4 & Med. Sea & - & JX473698 \\
\hline \multicolumn{7}{|l|}{ B. oviforme } \\
\hline B. oviforme & $20 B$ & Oithona sp. & 1 & NW Med. Sea & JX473666 & JX473666 \\
\hline B. oviforme & 31B & O. similis & 1 & NW Med. Sea & - & JX473680 \\
\hline B. oviforme & $33 \mathrm{~B}$ & O. similis & 1 & NW Med. Sea & - & JX473681 \\
\hline
\end{tabular}


Table A1 | Continued.

\begin{tabular}{|c|c|c|c|c|c|c|}
\hline Species & Isolate & Host & $\begin{array}{l}\text { Number of Blastodinium } \\
\text { ind. per host }\end{array}$ & Sampling site & SSU & ITS \\
\hline \multicolumn{7}{|l|}{ B. pruvoti } \\
\hline B. pruvoti & GA51 & Clausocalanus sp. & 5 & Atlantic Ocean & FJ541189 & - \\
\hline B. pruvoti & BP01 & Clausocalanus sp. & 2 & NW Med. Sea & - & JX473683 \\
\hline \multicolumn{7}{|l|}{ B. spinulosum } \\
\hline B. spinulosum & BCLO4 & Clausocalanus sp. & 10 & NW Med. Sea & HQ226071 & - \\
\hline B. spinulosum & BSP02 & Clausocalanus sp. & 20 & NW Med. Sea & HQ226072 & - \\
\hline B. spinulosum & BOUM35 & Not determined & 1 & Med. Sea & JN257671 & JX473699 \\
\hline B. cf. spinulosum & BCL01 & Clausocalanus sp. & 9 & NW Med. Sea & JX473663 & - \\
\hline B. spinulosum & GA41 & P. parvus & 13 & Atlantic Ocean & - & JX473684 \\
\hline Blastodinium sp. & SCM38C31 & Env. sequence & & Sargasso Sea & AY664984 & - \\
\hline Blastodinium sp. & SCM16C36 & Env. sequence & & Sargasso Sea & AY664982 & - \\
\hline Blastodinium sp. & ZZ0053180 & Env. sequence & & Florida Straits & EU818565 & - \\
\hline Blastodinium sp. & ZZ0053167 & Env. sequence & & Florida Straits & EU818553 & - \\
\hline Blastodinium sp. & BOUMD9 & Farranula cf. rostrata & 2 & Med. Sea & JN257679 & JX473703 \\
\hline Blastodinium sp. & BOUM29 & Not determined & nd & Med. Sea & JN257672 & JX473704 \\
\hline Blastodinium sp. & BOUM3 & Not determined & nd & Med. Sea & JN257673 & JX473705 \\
\hline Blastodinium sp. & BOUM4 & Farranula rostrata & nd & Med. Sea & JN257678 & JX473706 \\
\hline Blastodinium sp. & BOUM7 & Not determined & nd & Med. Sea & JN257681 & - \\
\hline Blastodinium sp. & BOUM21 & Not determined & nd & Med. Sea & JN257667 & JX473707 \\
\hline Blastodinium sp. & BOUM27 & Not determined & nd & Med. Sea & JN257668 & JX473708 \\
\hline
\end{tabular}

